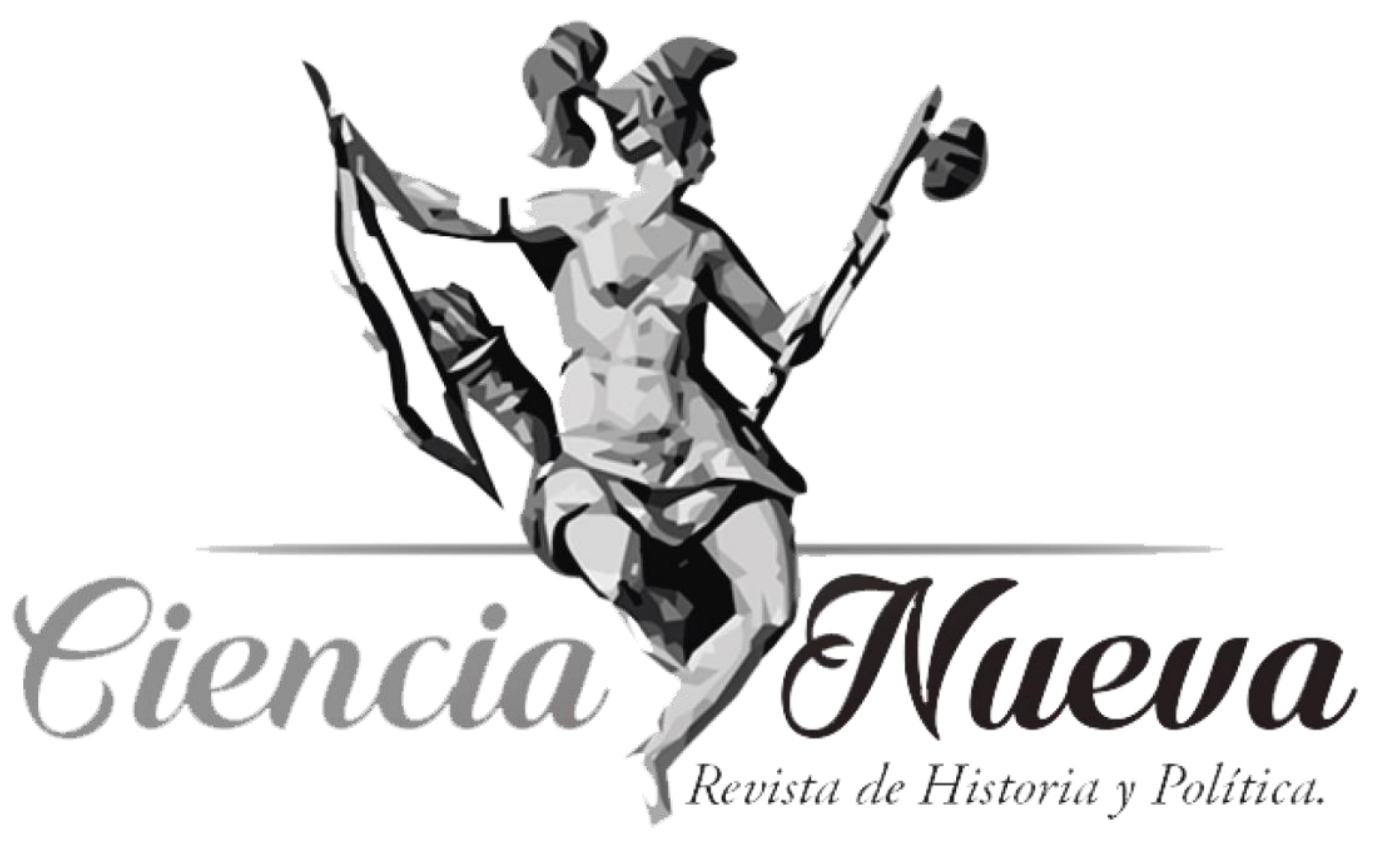

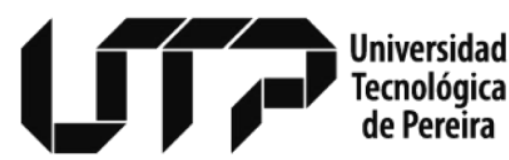

Maestría en Historia

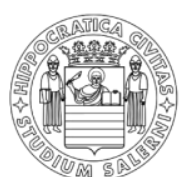

UNIVERSITÀ DEGLI STUDI DI SALERNO

Maestría en Ciencia Política

DOSSIER

Dr. Luis Ervin Prado Arellano, Editor invitado

\title{
EL EJECUTIVO FRENTE AL CONGRESO EN LAS PRIMERAS DÉCADAS DE LA EXPERIENCIA REPUBLICANA \\ COLOMBIANA, 1821-1840
}

EXECUTIVE POWER AGAINST CONGRESS IN THE FIRST DECADES OF THE COLOMBIAN REPUBLICAN EXPERIENCE, 1821-1840 DOI: https://doi.org/10.22517/25392662.23211

Armando Martínez Garnica

pp. 124-159

Vol. 3 Núm. 2 | Julio-Diciembre de 2019

Pereira, Colombia 


\title{
EL EJECUTIVO FRENTE AL CONGRESO EN LAS PRIMERAS DÉCADAS DE LA EXPERIENCIA REPUBLICANA COLOMBIANA, 1821-1840*
}

\author{
Executive Power against Congress in the First DeCADES OF THE Colombian \\ REPUBLICAN EXPERIENCE, 1821-1840
}

Armando Martínez Garnica ${ }^{* *}$

armandom09@gmail.com

ORCID: http://orcid.org/0000-0001-5966-175X

\author{
Recibido: 21 de octubre de 2019. \\ Revisado: 11 de diciembre de 2019. \\ Aceptado: 14 de diciembre de 2019. \\ Publicado: 30 de diciembre de 2019 .
}

\section{Resumen}

El ideal republicano del equilibrio de los poderes públicos fue garantizado por el ideario liberal de los constituyentes que se reunieron en el Congreso Constituyente de la Villa del Rosario de Cúcuta, cuando el ordenamiento constitucional concedió la preeminencia al Congreso, quien obtuvo la facultad para crear las cortes de justicia y los juzgados inferiores de la República. Pero durante las décadas de 1820 y 1830, el equilibrio se jugó entre el Ejecutivo y las cámaras legislativas. Este artículo examina de cerca cómo se construyó ese equilibrio de poderes públicos.

Palabras claves: Poder Ejecutivo, Poder Legislativo, equilibrio de poderes, régimen republicano.

\section{Summary}

The republican ideal of the balance of public powers was guaranteed by the liberal ideology of the constituents that met in the constituent congress of the town Villa del Rosario de Cúcuta, when the constitutional order granted the preeminence to Congress, that obtained the power to create the courts of justice and the lower courts of the Republic. But during the 1820 s and 1830 s, the balance was played between the Executive and the legislative chambers. This article closely examines how that balance of public powers was built.

Keywords: Executive power, Legislative power, balancing of powers, republican regime.

\footnotetext{
* Este documento respeta las directrices y normas dispuestas en la Declaración de Ética de Publicación de Ciencia Nueva, Revista de Historia y Política. Esta declaración puede consultarse en la página web de la revista: http://revistas.utp.edu.co/index.php/historia

** Doctor en Historia por el Colegio de México (México) y posdoctor en Historia de la Universidad Andina Simón Bolívar (Ecuador). Ex director del Archivo General de la Nación (Colombia).
} 


\section{Introducción}

$\mathrm{E}$ n el informe ejecutivo anual que el presidente del Estado de la Nueva Granada leyó ante los legisladores de 1836 fue recordada la empresa común, "ardua y progresiva", que desde 1821 habían acometido los dos principales poderes públicos: "nada menos que formar una nación, y una nación republicana e ilustrada, de un pueblo que por siglos fue colonia española". En esta ocasión el jefe del Poder Ejecutivo ofreció nuevamente al Poder Legislativo su cooperación:

...no solo por el deber que tiene de prestarla a todos los actos que expidiereis conforme a vuestros poderes, sino por el interés que tiene en la dicha común, en el honor del congreso y en el crédito de nuestra patria ${ }^{2}$.

Un año después, al presentar el último informe de su última administración, Francisco de Paula Santander señaló la contrapartida de esa cooperación:

Mis deseos y mis esfuerzos para favorecer los intereses de mi patria habrían sido inútiles e ineficaces si no hubiera prestado su poder el cuerpo legislativo, y si los agentes del gobierno no hubieran empleado el mayor celo en cumplir su voluntad.

Resultaba entonces, en su experimentada convicción, que la eficaz realización del sistema representativo adoptado por la república tenía como condición "la cooperación del poder legislador para hacer el bien que el poder ejecutivo desea, y evitar el mal, que justamente teme". Efectivamente, para hacer el bien público, tanto la Constitución de Colombia como la Constitución de la Nueva Granada habían concedido al presidente del Ejecutivo el deber de "instruir al congreso sobre el estado del país en todos sus ramos, e indicarle las reformas que deben hacerse en beneficio del pueblo". Y esto era así porque la práctica de la administración pública y la experiencia que de ella se derivaba eran elementos indispensables para la formación de las leyes, pues sin ellos se arriesgaba incurrir "en el grave mal de que la filosofía de los legisladores se halle deficiente o inaplicable en la práctica". Para evitar los males públicos, el Ejecutivo tenía que resistir "las desmesuradas exigencias de la exaltación"" que surgían en las cámaras legislativas, fuente de leyes "deficientes o inaplicables en la práctica", gracias al poder de objeción que le había otorgado la Constitución ${ }^{3}$.

Esa solidaridad —y delicado equilibrio — de los poderes legislativo y ejecutivo del régimen republicano que fue adoptado por los constituyentes de la Villa del Rosario de Cúcuta (1821) y de Bogotá (1832), fue experimentada íntimamente por el "hombre necesario" durante tres lustros: el general Francisco de Paula Santander. Por haber sido el jefe auténtico del Poder Ejecutivo como vicepresidente de Colombia — dada la ausencia del presidente durante todo su primer período de gobierno- y como primer presidente constitucional de la Nueva Granada, ya que fue quien dispuso de la experiencia histórica original de ese equilibrio de poderes.

Es por ello que este artículo, dirigido al registro histórico de la actuación del Ejecutivo frente al Congreso en las dos primeras décadas de la experiencia republicana colombiana (1821-1840), necesariamente tiene que tener al general Santander como actor principal de la escena política: fue él quien, ante las cinco legislaturas constitucionales de

\footnotetext{
${ }^{1}$ Francisco de Paula Santander, "Mensaje del presidente de la República al Congreso de la Nueva Granada, $1^{\circ}$ de marzo de 1836", Gaceta de la Nueva Granada, 232, 6 de marzo de 1836.

2 Santander, "Mensaje del presidente...".

${ }^{3}$ Francisco de Paula Santander, "Mensaje del presidente de la República al Congreso de la Nueva Granada, $1^{\circ}$ de marzo de 1837”, Gaceta de la Nueva Granada, 286, 5 marzo 1837.
} 
la experiencia colombiana (1823 a 1827), y ante las cinco primeras legislaturas constitucionales de la Nueva Granada (1833 a 1837), indicó "las mejoras y reformas" que debían ser convertidas en leyes por el Congreso. De un lado y del otro quien objetó todas las leyes y decretos que sufrieron ese control del Ejecutivo entre 1823 y 1837 . Como se recuerda, el Libertador presidente gobernó efectivamente desde 1828 sin la contraposición de las cámaras legislativas, y las relaciones del ejecutivo con las legislaturas de 1838-1840 fueron responsabilidad del presidente José Ignacio de Márquez, quien había sido un asiduo miembro del Consejo de Gobierno durante el tiempo de la administración granadina del general Santander.

La exposición de la actuación del Poder Ejecutivo frente al Poder Legislativo durante esos tres lustros seguirá el orden mencionado por el general Santander en 1837: primero, identificará la acción positiva de intentar hacer el bien de la nación por el procedimiento de aconsejar a las cámaras legislativas la aprobación de nuevas leyes dirigidas al logro de ese fin; después, identificará la acción negativa que consistió en objetar las leyes aprobadas por las cámaras legislativas para evitar el mal y los perjuicios que podrían seguirse tanto al ejecutivo como al pueblo colombiano o granadino.

Desde el mismo momento en que comenzaron las sesiones de la primera legislatura constitucional de 1823, el vicepresidente Santander recordó que, conforme a los artículos de la primera sección del título IV de la Constitución colombiana, el Poder Ejecutivo intervenía en la formación de las leyes de dos maneras: dándoles su sanción cuando las hallare "justas y arregladas" o cuando las objetase, y además cuando indicara al Congreso las mejoras y reformas que podían hacerse en los distintos ramos de la administración pública. Para empezar, solicitó a los primeros legisladores que determinaran la etiqueta que seguirían en sus relaciones mutuas: el tratamiento que debían recibir los presidentes de las cámaras de parte del ejecutivo, y el lugar que ocuparían el presidente y los secretarios del ejecutivo cuando asistieran a sus sesiones. Esta legislatura dio respuesta con la ley que aprobó el 2 de julio de 1823: el ejecutivo debía tratar de "excelencia" a los presidentes de las dos cámaras y los secretarios del despacho podrían tomar asiento "indistintamente entre los senadores y representantes" cuando concurrieran a las sesiones legislativas ${ }^{4}$.

\section{"Indicar las reformas que deben hacerse en beneficio del pueblo"}

El artículo 129 de la Constitución de la República de Colombia aprobada en la Villa del Rosario de Cúcuta (1821) impuso al presidente del Ejecutivo la obligación de leer, el día en que se abrían las sesiones anuales de las dos cámaras legislativas, un informe sobre "el estado político y militar de la nación, de sus rentas, gastos y recursos, y le indicará las mejoras o reformas que pueden hacerse en cada ramo". Esta tradición colombiana se mantuvo exactamente en el Estado de la Nueva Granada por el artículo 111 de su primera Constitución, que también obligó al presidente a leer anualmente un informe sobre "el estado político y militar de la nación, de sus rentas, gastos y recursos, indicándoles las mejoras y reformas que puedan hacerse en cada ramo". Una revisión de la decena de informes anuales que el general Santander leyó ante las cámaras legislativas

\footnotetext{
${ }^{4}$ La resolución inicial del Senado se inclinó por el tratamiento de "señoría" para los presidentes de las dos cámaras. Una comisión especial nombrada por el Senado (Manuel José Hurtado, José Miguel Uribe y Francisco Soto) se inclinó por el tratamiento de "señor presidente", de acuerdo con "el espíritu de nuestras instituciones, con el sistema popular representativo y con ejemplo de otros países que han sido o son libres". Pero la Cámara de Representantes se inclinó por el tratamiento de "excelencia" para los presidentes de las dos cámaras. Finalmente cedió el Senado en su posición inicial "por dar una señal de deferencia" y porque consideró que si los presidentes de las cortes superiores de justicia gozaban de la prerrogativa de ser tratados de "excelencia" no era "una monstruosidad que se declarasen así a los presidentes de las cámaras legislativas". Archivo General de la Nación, serie Archivo Histórico Legislativo, Senado, 22, proyectos de ley pendientes, negados y mandados a archivar, f. 96-110v.
} 
de Colombia y de la Nueva Granada durante los años 1823 a 1827 y 1833 a 1837 comprueba que efectivamente esa atribución constitucional del presidente del Ejecutivo fue cumplida al pie de la letra, como se muestra enseguida.

$\mathrm{Al}$ abrir las sesiones de la primera legislatura constitucional de Colombia en 1823, puso Santander sus mejores esperanzas en la acción legislativa:

Leyes sobrias, reformas saludables y actos que derramen por todas partes beneficencia y dicha, y que consoliden la obra de doce años de sacrificios, me prometo que serán el resultado de vuestras meditaciones, y el óptimo fruto que recibirán los pueblos con gozo y alegría.

De inmediato pasó a recomendar "con el mayor encarecimiento la suerte del pueblo colombiano, cuyos sacrificios se han reducido al estado de necesitar de toda la protección de leyes sabias y benéficas". Como la guerra civil había aniquilado la población, la agricultura y el comercio, pidió hacer todo lo posible para "revivir estos manantiales de la riqueza pública e individual" con leyes de fomento capaces de poner al "heroico pueblo de Colombia en estado de reproducirse y enriquecerse", así como nuevas leyes para "la propagación y progreso de los establecimientos literarios y científicos". Convocó a la Cámara de Representantes a emplear sus primeras sesiones, preferencialmente, a acordar leyes que resolvieran el urgente problema de escasez de recursos fiscales, "porque sin recursos pecuniarios el ejecutivo no puede llenar sus deberes, ni la nación disfrutar de su independencia y libertad. A la cámara de representantes más particularmente dirijo mi voz en la materia expresada". Sugirió legislar inmediatamente sobre dos rentas que prometían abundantes recursos: la del estanco de tabaco, que requería anticipos y recursos, y la de aduanas, que exigía "leyes bien calculadas". Pidió también la abolición de las exacciones que pesaban de antaño sobre el clero (mesada eclesiástica, anualidades y media anata) y, sobre todo, atender el pago de las deudas externas contraídas por los gastos de la guerra con comerciantes particulares, pues en ello estaba en juego el honor nacional: "Somos deudores y debemos pagar haciendo el más penoso sacrificio". El Ejecutivo esperaba la expedición de una ley por medio de la cual se pudiera pagar los intereses y comenzar la lenta amortización del principal ${ }^{5}$.

La solidaridad de la legislatura de 1823 con las peticiones del vicepresidente fue efectiva, a juzgar por los decretos y leyes fiscales que aprobó con rapidez: cobrar por este año a todos los ciudadanos, según el monto de sus bienes o de sus ingresos, un subsidio personal (decreto del 31 de mayo); autorizar al Poder Ejecutivo a emitir pagarés a cuenta de un empréstito europeo de 30 millones de pesos fuertes que consolidara todas las deudas e intereses anteriores (ley del 7 de julio) y otro empréstito de 500.000 pesos (decreto del $1^{\circ}$ de agosto), prohibir la importación de aguardientes y tabacos extranjeros para proteger los estancos nacionales (leyes del 7 de julio y 5 de agosto), mantener la vigencia del real estanco de la pólvora (ley del 7 de julio), arrendar las salinas de Zipaquirá y todas las minas nacionales (decretos del $1^{\mathrm{o}}$ y 5 de agosto), consolidar en un único arancel todos los derechos de importación por las aduanas y penalizar a todos sus defraudadores ( 5 de agosto). Si no aprobó la abolición de las exacciones que pesaban sobre el clero fue porque el vicepresidente objetó el texto de la ley para ampliar sus beneficios a todos los empleados públicos.

Continuando con esa cooperación, la legislatura de 1824 aprobó el decreto que abolió la mesada eclesiástica, las medias anatas y la anualidad con que el gobierno español había gravado a los eclesiásticos (28 de marzo); introdujo otra contribución extraordinaria por una sola vez (18 de junio), prohibió la importación de sales extranjeras (10 de julio), restituyó el

\footnotetext{
${ }^{5}$ Francisco de Paula Santander, Mensaje del Poder Ejecutivo de Colombia a la apertura del Congreso Constitucional de la República de Colombia, Bogotá, 17 de abril de 1823 (Bogotá: Imprenta de Espinosa, 1823).
} 
cobro de la alcabala interna con el nombre de derecho de consumo (22 de julio), estableció un fondo y una caja de amortización para el pago de la deuda doméstica y extranjera ( 28 de julio), introdujo el primer Código Fiscal y ordenó el fomento de la renta de tabacos con los ingresos provenientes del empréstito inglés (20 de mayo).

A tal punto llegó la cooperación inicial de los dos poderes públicos que el vicepresidente se atrevió a solicitarle a la legislatura de 1823, "en nombre del inmortal fundador de la república de Colombia", la expedición de un decreto que le asignara una suma de dinero, "por vía de arbitrio, para que en su vejez y en el retiro de los negocios públicos pueda mantenerse con decoro y comodidad". Exactamente un mes después aprobaron los legisladores el decreto que le concedió una pensión de 30.000 pesos anuales durante el resto de su vida, la cual correría desde el día en que el Libertador terminase sus funciones como presidente $^{6}$.

Al abrir las sesiones de la tercera legislatura constitucional de 1825 , el vicepresidente pidió a los legisladores la expedición del primer plan general de estudios, cuya falta era cada día más necesaria para la propagación del método de Lancaster en la enseñanza primaria, el aumento de las casas de educación, el establecimiento de nuevas cátedras y la reforma de algunos colegios que eran todavía "víctimas de la antigua educación colonial". Pidió de nuevo una ley orgánica del Poder Judicial y otra para el ordenamiento político-administrativo de los departamentos y las provincias...

...persuadido de que estas dos leyes van a corregir los defectos de la administración de los departamentos y a mejorar en parte la de justicia, haciéndose un positivo y verdadero beneficio a los pueblos que con razón se han quejado de la extensa jurisdicción que abrazan los tres únicos tribunales de apelaciones, y del insignificante poder de las municipalidades ${ }^{7}$.

La respuesta positiva de los legisladores de 1825 se expresó en la aprobación de la ley orgánica del Poder Judicial (11 de mayo) y de la ley que aprobó el régimen político y económico de los departamentos y las provincias del territorio colombiano (11 de marzo). Por objeciones del Ejecutivo fue la siguiente legislatura la que aprobó, el 18 de marzo de 1826, tanto la primera ley orgánica de la instrucción pública como el decreto que autorizó al Ejecutivo para formar y mandar ejecutar el plan de estudios que regiría las escuelas y universidades públicas. Ante la legislatura de 1825 el Ejecutivo presentó, para examen y aprobación, los tratados de paz, amistad, navegación y comercio que había ordenado firmar con los gobiernos de los Estados Unidos de América y de la Gran Bretaña durante el año anterior. Convencidos por la promesa del vicepresidente de que en ellos se había adherido "al espíritu de civilización y humanidad que debe distinguir a los gobiernos de los pueblos libres", efectivamente ratificaron el 25 de marzo el tratado con los Estados Unidos y el 23 de mayo el tratado con el rey de Gran Bretaña e Irlanda.

Pero la quinta legislatura colombiana de 1827 fue escenario del primer gran desencuentro de los dos poderes públicos. Tal como había decretado la legislatura de 1825 , los mandatos constitucionales del primer presidente y del primer vicepresidente de Colombia se extinguirían al mediodía del 2 de enero de 1827, una vez se abrieran las sesiones de las dos

\footnotetext{
${ }^{6}$ Francisco de Paula Santander, "Comunicación dirigida al presidente de la Cámara de Representantes, Bogotá, 23 de junio de 1823”, en Cartas y mensajes del general Francisco de Paula Santander, comp. por Roberto Cortázar (Bogotá: Academia Colombiana de Historia, 1956), vol. X, 361-362. "Decreto que concede al Libertador presidente una pensión de treinta mil pesos anuales, durante su vida, Bogotá, 23 de julio de 1823. Sancionado el 26 de julio de 1823 por el vicepresidente”, en Codificación Nacional (Bogotá: Imprenta Nacional, 1924), tomo I, n. ${ }^{\circ} .115,233$.

${ }^{7}$ Francisco de Paula Santander, Mensaje del vicepresidente de Colombia encargado del Gobierno al Congreso de 1825, Bogotá, 2 de enero de 1825 (Bogotá: Imprenta de Espinosa, 1825). Biblioteca Nacional de Colombia, fondo Pineda, 928, n. ${ }^{\circ}$ 1. También en Gaceta de Colombia, 169 suplemento (9 de enero de 1825), 5-8.
} 
cámaras legislativas. Pero ocurrió que por falta de quorum no fue posible abrir las sesiones legislativas ese día, y entonces el vicepresidente tuvo que decretar que las sesiones se instalaran en Tunja, donde se hallaba enfermo el senador Alonso Uscátegui, quien completaría el quorum necesario. Así fue como las sesiones no pudieron instalarse sino el 2 de mayo, en el alojamiento donde estaba postrado dicho senador. Una vez realizada esta diligencia y elegidos los presidentes de las dos cámaras, regresaron todos a Bogotá, donde el vicepresidente pudo al fin leer su informe anual, con fecha del 12 de mayo.

El principal problema que tuvo que resolver esta legislatura, dividida en dos partidos de opinión llamados "liberal" y "servil" — un eco de los debates de las Cortes de Cádiz-, fue el de las renuncias a sus cargos en la segunda administración constitucional para la que habían sido elegidos durante el año anterior, tanto del Libertador presidente como del vicepresidente Santander. Como la bancada boliviana estaba dispuesta a aceptar la renuncia del vicepresidente y la bancada liberal la renuncia del Libertador, puede decirse que las tensiones partidistas afectaban a los dos poderes públicos. La necesidad de instalar un Ejecutivo legítimo forzó a los dos poderes a no aceptar la renuncia del vicepresidente, casi por unanimidad del Congreso, pero el 6 de junio de 1827 fue elegido como el día en que las dos cámaras legislativas resolverían definitivamente sobre las dos renuncias. Un relato de lo acontecido en esa sesión se debe al senador Francisco Soto y muestra bien el grado al que habían llegado las malas relaciones en el seno del Legislativo y el impacto de esa disputa de partidos de opinión en el deterioro de las relaciones con el Ejecutivo:

... cubierta la barra de serviles... los cosacos palmotearon... Jerónimo Torres, a quien se llama el capuchino por sus opiniones serviles, por su voz disgustante y por sus ingratos modales... El senador Azuero expuso que Bolívar, a su modo de entender, era un verdadero tirano... ${ }^{8}$.

Terminadas las vibrantes intervenciones se pasó a la votación nominal: por 50 contra 24 votos no fue admitida la renuncia del Libertador presidente, y por 70 contra 4 votos tampoco fue admitida la renuncia de Santander. Pero el daño político y moral ya estaba hecho. Los trabajos de esta legislatura se limitaron a proyectos relacionados con la gran convención constituyente que se convocó para el siguiente año en Ocaña, un evento que despertó grandes expectativas en todos los departamentos pero que cosechó el más estruendoso fracaso. Como consecuencia, las legislaturas constitucionales de Colombia no volvieron a reunirse nunca más, y el congreso constituyente de 1830, aunque sea llamado "admirable", no tuvo ninguna consecuencia política porque llegó demasiado tarde.

Elegido primer presidente del Estado de la Nueva Granada por su convención constituyente, Santander retornó en 1833 a la práctica de abrir las sesiones del Congreso con un informe anual en el que pedía reformas legislativas. Esta vez lo dijo con las siguientes palabras:

La necesidad de una legítima y saludable reforma administrativa es vital, y la solicito como el primer bien para el país. Os encarezco, pues, como más urgente, el plan de enseñanza e instrucción pública, la ley que designe y defina con claridad las facultades de las cámaras de provincia, y la de procedimiento judicial. Esta sola reforma en la administración interior del Estado tendrá inmensos resultados en favor del bienestar de la Nueva Granada, porque fundándose la verdadera prosperidad pública en la adquisición de medios para nuestra existencia física y para la conservación de nuestra existencia política, y en la seguridad de los derechos civiles del ciudadano, las cámaras de provincia proveerán a los primeros, la educación pública a los segundos, y la buena

\footnotetext{
${ }^{8}$ Francisco Soto, "Memorias para la historia de la Legislatura de Colombia en 1827, Bogotá, 4 de octubre de 1827”, en Mis padecimientos i mi conducta pública y otros documentos (Bogotá: Academia Colombiana de Historia, 1978),138-144. Las actas originales de la agitada sesión conjunta de las dos cámaras legislativas realizada el 6 de junio de 1827 pueden leerse en el Archivo General de la Nación, Archivo Histórico Legislativo, Senado, tomo 8, f. 134-156v.
} 
administración de justicia a los últimos? .

Respondiendo a estas solicitudes, la legislatura de 1834 aprobó la ley que estableció el nuevo régimen administrativo de las provincias, cantones y distritos parroquiales (19 de mayo), la ley orgánica de todos los tribunales de justicia de la república (10 de mayo) y la ley de procedimiento civil (14 de mayo). Por su parte, la legislatura de 1835 aprobó la ley que reformó el plan de enseñanza pública para las universidades granadinas (30 de mayo) y el decreto que dispuso la manera como debían redactarse los decretos y ordenanzas de las cámaras provinciales. Finalmente, la legislatura de 1837 dotó a la república de su primer Código Penal (27 de junio).

El último informe ejecutivo que Santander leyó ante la legislatura de 1837, cuando puso término a su carrera en la administración pública, fue un reconocimiento a su prolongado entendimiento con las cámaras legislativas. Una prueba de ello fue que en los siguientes dos años hizo su actividad política en el Senado. Su balance personal es un buen resumen de la acción positiva del Ejecutivo respecto del Legislativo, es decir, de la tarea de proponer las reformas que debían hacerse en beneficio del pueblo, para que los legisladores las debatieran y buscaran las mejores direcciones que debían dar a las leyes:

Libertad y orden, escuelas y caminos, alivio en las contribuciones, severa economía en su inversión, y estricta disciplina militar: he aquí en compendio el programa de los principios que me han regido en mi administración, y de que no me han hecho desviar ni los peligros, ni las pasiones más encarnizadas. Si debo a la Nueva Granada una inmensa suma de gratitud por los muchos honores con que me ha favorecido desde 1819, no es menor la que debo al Congreso, al ejército y a todos los buenos ciudadanos por los señalados servicios con que me han auxiliado, y por la confianza con que me han sostenido ${ }^{10}$.

\section{"Objetar las leyes inconvenientes para evitar perjuicios"}

El artículo 46 de la Constitución de la República de Colombia aprobada en la Villa del Rosario de Cúcuta el 30 de agosto de 1821 estableció un delicado equilibrio entre el Poder Ejecutivo y el del Congreso en el tema de los proyectos de nuevas leyes republicanas, como puede apreciarse en su texto:

Artículo 46. Ningún proyecto o proposición de ley constitucionalmente aceptado, discutido y determinado en ambas cámaras podrá tenerse por ley de la República hasta que no haya sido firmado por el Poder Ejecutivo. Si éste no creyere conveniente hacerlo, devolverá el proyecto a la Cámara de su origen, acompañándole sus reparos, sea sobre falta en las fórmulas, o en lo sustancial, dentro del término de diez días contados desde su recibo.

El Poder Ejecutivo de Colombia fue entonces investido de dos poderes limitantes del Poder Legislativo: primero, del poder para sancionar con su firma las leyes debatidas y aprobadas en las dos cámaras legislativas, sin la cual no tendrían fuerza legal alguna; segunda, del poder para objetar con sus reparos el texto de las leyes ya aprobadas, devolviendo el proyecto a la cámara de origen. En este caso, la cámara tenía dos opciones: archivar el proyecto y registrar los reparos en las actas de sus sesiones, o emprender la difícil acción de discutir nuevamente la materia sobre la cual versaba la ley, conseguir su aprobación por segunda vez con una mayoría cualificada de las dos terceras partes de los miembros presentes y remitirla a la otra cámara con los reparos del Poder Ejecutivo,

\footnotetext{
${ }^{9}$ Francisco de Paula Santander "Mensaje dirigido al Congreso de la Nueva Granada, Bogotá, $1^{\circ}$ de marzo de 1833”, en Administraciones de Santander, comp. por Luis Horacio López (Bogotá: Fundación Francisco de Paula Santander, 1990), tomo III, 106.

${ }^{10}$ Francisco de Paula Santander, "Mensaje del presidente de la República al Congreso de la Nueva Granada, $1^{\circ}$ de marzo de 1837”, Gaceta de la Nueva Granada, 286 (5 marzo 1837).
} 
donde tendría que ser aprobada con la misma mayoría cualificada. Adicionalmente, el Poder Ejecutivo fue investido del poder de sanción sobre todas las resoluciones, decretos, estatutos y actos legislativos de las dos cámaras legislativas - excepto las referidas al aplazamiento o suspensión de sus sanciones-, los decretos para solicitar informes o formar comisiones de su seno, los juicios sobre calificación de las calidades de sus miembros, sus reglamentos de debates y cualquier otro acto en que no fuese necesaria la concurrencia de las dos cámaras.

No obstante, esta preeminencia del Poder Ejecutivo sobre las iniciativas del Poder Legislativo fue equilibrada con las atribuciones especiales que el artículo 55 concedió al Congreso en los asuntos que en el régimen del anterior Estado absolutista estaban reservados al capricho del monarca: la conscripción y organización de los ejércitos, el equipamiento de la marina, las ordenanzas militares de mar y tierra, las declaratorias de guerra y la negociación de la paz, la aprobación de los tratados varios con otros Estados, los indultos generales por motivos de conveniencia pública, la licencia para el paso de tropas de otros Estados por el territorio nacional, la imposición de todas las contribuciones fiscales y la aprobación de los presupuestos de los gastos públicos.

El ideal republicano del equilibrio de los dos principales poderes públicos parecía entonces garantizado por el ideario liberal de los constituyentes que se reunieron en el congreso constituyente de la villa del Rosario de Cúcuta, pero el ordenamiento constitucional concedió la preeminencia al Congreso, quien obtuvo la facultad para crear las cortes de justicia y los juzgados inferiores de la república. Por algo el ordenamiento del Poder Legislativo antecedió al del Poder Ejecutivo tanto en el debate del proyecto constitucional como en el texto de la carta fundamental que resultó aprobado bajo los títulos IV y V.

Contra esa preeminencia del Legislativo se rebeló el Libertador presidente en el mensaje que dirigió a los "representantes del Pueblo de Colombia" que se reunieron en 1828 en la ciudad de Ocaña para debatir el texto de una nueva constitución. Fue entonces cuando denunció la ineficiencia política del arbitrio de objeción de las leyes que había sido concedido al Ejecutivo, "tanto más ineficaz cuanto que se ofende la delicadeza del Congreso con la contradicción". La queja del presidente del Ejecutivo era grave: "El Congreso puede insistir victoriosamente, hasta con el voto de la quinta o con menos de la quinta parte de sus miembros, lo que no deja medio de eludir el mal". Las cámaras legislativas ni siquiera dejaban entrar libremente a sus sesiones a los secretarios del despacho ejecutivo para explicar los motivos de las objeciones. El derecho de presentar proyectos de ley había quedado exclusivamente en el Legislativo, "que por naturaleza está lejos de conocer la realidad del gobierno y es puramente teórico". La conclusión del jefe del Ejecutivo fue dramática: el gobierno de la República había quedado "esencialmente mal constituido" porque se había hecho del Legislativo todo "el cuerpo soberano", cuando no debería ser más que uno de sus miembros. Esa mala distribución de los poderes le había dado al Legislativo el poder para someter al Ejecutivo y "mucha más parte en la administración general que la que el interés legítimo permite". Era claro para él que el Ejecutivo no era igual de poderoso que el Legislativo, sino "un brazo débil del poder supremo porque el Congreso se injiere en sus funciones naturales sobre lo administrativo, judicial, eclesiástico y militar”. Este diagnóstico le permitió al jefe del Ejecutivo convocar a los constituyentes de Ocaña a oír el grito de la patria que pedía "un gobierno firme, poderoso y justo"11.

11 "Mensaje del Libertador presidente a la Gran Convención de los representantes del Pueblo en Convención Nacional. Bogotá, 29 de febrero de 1828", Gaceta de Colombia, 342-suplemento ( $1^{\circ}$ de mayo de 1828), 56. Las objeciones que el vicepresidente Santander interpuso a muchos proyectos de ley aprobados por las 
Como se sabe, la gran Convención de Ocaña se disolvió sin alcanzar su propósito. Ante la ilegitimidad que cayó sobre la Constitución de 1821 pasó el Libertador presidente a dictar, el 27 de agosto de 1828, un decreto que serviría como "Ley Constitucional" del Estado hasta 1830. Por efecto de este nuevo orden legal quedaron disueltas las cámaras legislativas de Colombia y el jefe supremo del Estado quedó con la facultad de "alterar, reformar o derogar las leyes establecidas". Antes de que cumpliese un mes en esta posición política eminente, o "tiránica" según algunos, un grupo de exaltados jóvenes liberales asaltó el palacio presidencial y estuvo a punto de asesinar al jefe supremo del Estado.

Las tradiciones colombianas en el tema del derecho del Ejecutivo a objetar leyes aprobadas por el Legislativo fueron reproducidas en la Constitución que aprobó el 29 de febrero de 1832 la Convención constituyente del Estado de la Nueva Granada, pues el artículo 83 dejó sin fuerza legal cualquier proyecto de ley o decreto que no fuera sancionado con su firma por el Poder Ejecutivo, quien llegara a juzgar inconveniente su aplicación lo devolvería a su cámara de origen, adjuntando sus observaciones. En estos casos, la cámara tendría las mismas dos opciones: archivar el proyecto o aprobarlo de nuevo por mayoría cualificada y pasarlo a la otra cámara. Solo si a juicio de la mayoría cualificada de esta otra se hallaban infundadas las observaciones del Poder Ejecutivo, retornaría el proyecto a este para su sanción y ejecución, sin que ya pudiera denegarse a hacerlo.

La contrapartida en favor del poder del Congreso fue concedida por el artículo 75 de esta Constitución como una atribución heredada de la experiencia colombiana: el perfeccionamiento de las elecciones del presidente y del vicepresidente cuando, verificados los escrutinios, ninguno de los candidatos hubiera obtenido la pluralidad absoluta de los votos de los electores de las asambleas electorales. En este caso, el Congreso elegiría entre los tres candidatos que en los registros electorales hubiesen obtenido el mayor número de votos ${ }^{12}$.

El procedimiento del perfeccionamiento de la elección presidencial fue aplicado durante la experiencia del Estado de la Nueva Granada a los debates electorales que llevaron a la presidencia a José Ignacio de Márquez, Pedro Alcántara Herrán, Tomás Cipriano de Mosquera y José Hilario López. Como Francisco de Paula Santander fue elegido su primer presidente por el congreso constituyente, puede subrayarse que mientras estuvieron vigentes las dos primeras constituciones granadinas, entre $1832 \mathrm{y}$ 1853, solo el general José María Obando pudo decir que no le debía su nombramiento en el cargo al Congreso. Y así había ocurrido también durante la primera década de la experiencia colombiana, pues los generales Bolívar y Santander fueron elegidos para sus cargos de presidente y vicepresidente por el congreso constituyente de la Villa del Rosario de Cúcuta, y Santander fue elegido vicepresidente para su segundo período por el procedimiento perfeccionador previsto en el artículo 73 constitucional en la legislatura de 1826 (15 de marzo), con lo cual solo el general Bolívar fue elegido para su segundo

legislaturas de 1823 a 1827, la mayoría atendidas por los legisladores, desmiente la apreciación del Libertador presidente respecto de la "ineficacia" del derecho de objeción concedido al Ejecutivo por el artículo 46 de la Constitución.

${ }^{12}$ Los artículos 73 a 76 de la Constitución colombiana de 1821 establecieron que en los casos en los que ningún candidato a la presidencia o vicepresidencia de Colombia obtuviese las dos terceras partes de los votos de los electores que habían concurrido a las asambleas electorales de las provincias, correspondía al congreso perfeccionar esa elección: primero, votaría por los tres nombres que hubieran obtenido mayor número de sufragios, y si ninguno de estos lograse las dos terceras partes de los votos de los congresistas se procedería a votar, en segunda ronda, por los dos nombres que hubieran obtenido mayor número de sufragios. Este perfeccionamiento se haría en una única sesión permanente y no terminaría hasta que uno de los dos finalistas no obtuviera la mayoría cualificada. 
período por las asambleas electorales del país.

Para más inri, con la emergencia de la nueva generación liberal radical del 7 de marzo1849 y su instalación en el despacho del presidente José Hilario López, además de copar la mayoría de las sillas de la Cámara de Representantes, se produjo un nuevo equilibrio de poderes más favorable al Congreso. Efectivamente, la constitución que estos jóvenes liberales (bautizados "gólgotas" por sus contradictores) lograron aprobar el 20 de mayo de 1853 - partiendo de un proyecto escrito por Florentino González y menos de dos meses después del ascenso del general Obando a la presidencia - puso fin al poder efectivo del Ejecutivo para objetar las leyes aprobadas por las cámaras legislativas. El artículo 38 de esta carta apenas parecía concederle al Poder Ejecutivo la atribución de poner a continuación del proyecto de ley aprobado por las Cámaras un decreto de ejecución, si lo juzgaba conveniente. Pero si llegaba a juzgar que era "inconstitucional, perjudicial o defectuoso", podía devolverlo al Congreso solo para su "reconsideración". En este caso, el artículo 39 estableció que las dos cámaras legislativas darían un nuevo debate al proyecto, y su resultado pasaría de nuevo al Poder Ejecutivo para su ejecución, que ya no podría rehusar. Como podría ocurrir que las dos cámaras tuviesen discordancias en un proyecto de ley objetado, entonces procederían a reunirse en un solo cuerpo y, después de un solo debate, definirían por mayoría absoluta de votos. En contrapartida, el procedimiento perfeccionador de la elección presidencial por el Congreso fue abolido, dada la introducción del sufragio universal masculino y secreto, un sistema en el cual los electores directos definirían por mayoría relativa de votos.

Antes de la aprobación de este nuevo ordenamiento constitucional ya el presidente José Hilario López había renunciado a su poder de objeción de los proyectos de ley aprobados por las cámaras legislativas, como lo reconoció abiertamente al final de su mandato:

\footnotetext{
Ofrecí inclinarme respetuoso delante de la opinión, i a la voz de las mayorías de las Cámaras, representantes legales de la voluntad nacional; i así lo he practicado, como la Legislatura ha tenido la ocasión de advertirlo, pues si bien la Constitución, dándome el derecho de objetar los proyectos de lei, me concede también el de insistencia cuando el Congreso reproduce en unas mismas sesiones un proyecto objetado por primera vez, yo he tenido la deferencia republicana de ejecutar la voluntad de los legisladores en el único caso que ha ocurrido de esta naturaleza ${ }^{13}$.
}

Desde el primer día de su Administración el presidente López supo que tendría que "inclinarse respetuoso" ante el empoderamiento de la nueva generación gólgotaliberal ("gólgota") en las cámaras legislativas, pues su autonomía para nombrar sus primeros secretarios del despacho ejecutivo tuvo que ser cedida en favor del Poder Legislativo. Antes de posesionarse en la silla presidencia, evento que ocurrió el $1^{\circ}$ de abril de 1849, se había propuesto nombrar un ministerio integrado por "personas de precedentes honrosos, de buena posición en la sociedad, de carácter independiente y con capacidad reconocida, sin reparar mucho en los colores políticos”. Ofreció entonces la secretaría de Hacienda al doctor Clímaco Ordóñez, miembro del Partido Conservador; la secretaría de Guerra al general Tomás Herrera, un liberal que no había trabajado por su elección, y las otras dos secretarías a dos connotados publicistas radicales: Ezequiel Rojas (Relaciones Exteriores) y Francisco Javier Zaldúa (Gobierno). Pero la oposición que este cálculo despertó entre el Partido Conservador, que a través de uno de sus parlamentarios manifestó que ningún conservador admitiría empleos en su Administración, y entre los radicales que habían luchado por su causa en las cuatro votaciones perfeccionadoras que

13 José Hilario López, Mensaje del presidente de la República al Congreso Constitucional de la Nueva Granada (Bogotá: Imprenta de Echeverría Hermanos, 1853), 4. 
tuvieron que realizarse en el convento de Santo Domingo, lo obligaron a adoptar una postura insólita en un titular del Poder Ejecutivo granadino: delegar el nombramiento de los secretarios del Poder Ejecutivo al juicio de los legisladores radicales que habían luchado por su elección.

Efectivamente, la necesidad de contar con el apoyo de las cámaras legislativas para la aprobación de la agenda de reformas políticas que había prometido a sus electores, en la circunstancia de "una guerra cruel y sin treguas" que le había declarado el Partido Conservador, lo compelió a convocar a una reunión a los senadores y representantes que habían contribuido a su elección, en una residencia particular de Bogotá, "para que me indicaran los ciudadanos en quienes debía fijarme para componer el ministerio, con cuya opinión me conformé". Esta terrible decisión para un representante de la majestad del Poder Ejecutivo, que incluso lo obligó a evaluar la opción de renunciar al cargo de presidente que acababa de obtener, tuvo que justificarla "ante la Historia" con las siguientes palabras:

Con este paso, tan político como prudente, evitaba yo la enajenación de la buena voluntad de algunos de mis amigos, cuya susceptibilidad no me era desconocida, que pudieran considerarse agraviados por haber preferido a otros, cosa que la experiencia me ha enseñado debía suceder infaliblemente y que habría producido, en ese conflicto, el perder el endeble apoyo de las Cámaras y de la prensa, cuando más se necesitaba de esos elementos para dar vigor al Gobierno y sostener el orden público. Yo tengo todavía la conciencia de haber obrado de la única manera posible en la disyuntiva que se me presentaba: de caer tristemente y aplazar para un tiempo remoto las grandiosas reformas que se han hecho durante el cuatrienio de mi mando, o proceder en el sentido que lo hice, para obviar tantos y tan graves inconvenientes como los que se me presentaban en aquella posición enteramente anormal ${ }^{14}$.

Las bancadas liberales de las dos cámaras legislativas escogieron entonces el ministerio ejecutivo de 1849 , si bien tuvieron en cuenta un consejo dado por el general López: no escoger a los secretarios extrayéndolos de su propio seno, pues se corría el riesgo de que quedase en minoría "el partido parlamentario de la nueva Administración". La consecuencia política que nadie había planeado, pero que de hecho ocurrió, fue la de que la Administración López (1849-1853) se convirtió abiertamente en el primer gobierno de partido de cuantos hasta entonces se habían encargado del Ejecutivo en la Nueva Granada. Un caso que prueba esta percepción es el del general José Acevedo Tejada, quien fue escogido por el presidente López como secretario de Relaciones Exteriores del despacho ejecutivo en reconocimiento a los servicios prestados por su familia al país, así como a su "moderación e inteligencia".

La "amarga censura" que el Partido Liberal hizo al presidente por esta elección, teniendo a la vista la calidad de conservador del nombrado, fue de tal calibre que el presidente se encontró forzado "a suplicarle que renunciara a su puesto, manifestándole que si creía que no debía renunciar, yo no estaba dispuesto a removerlo, y sí resuelto a

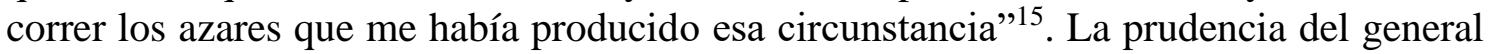
Acevedo le permitió al presidente salir de la azarosa circunstancia, pero en cambio no pudo librarlo de la humillación personal. Solo hasta que el presidente nombró para esa

14 José Hilario López, Para la historia (París: Imprenta D’Aubusson y Kugelmann, 1856), 17-20. Solamente "los estímulos del honor y del deber opusieron una resistencia tenaz" a la opción de renunciar a la presidencia. En esas adversas circunstancias políticas tuvo que resignarse a tomar tan terrible decisión para el honor del Poder Ejecutivo "y seguir allanando los obstáculos que se me oponían, sufriendo siempre los tiros encarnizados de la maledicencia y esperando que mi conducta constitucional, honrosa y moderada, aunque enérgica, desarmara a mis procaces calumniadores y diera brío y confianza a mis amigos", López, Para la historia..., 21.

${ }^{15}$ López, Para la historia..., 25, nota 1. 
Secretaría a Victoriano de Diego Paredes, reconocido liberal, no cesaron los ataques de la prensa. Los otros tres secretarios del despacho fueron reconocidos liberales: Francisco Javier Zaldúa (Gobierno), Manuel Murillo Toro (Hacienda) y el general Valerio Francisco Barriga (Guerra y Marina). El líder de la bancada liberal, Ezequiel Rojas, fue reservado para que no dejase de concurrir al Congreso.

Como era de esperar, los constituyentes "regeneradores" que en 1886 aprobaron una nueva constitución y restablecieron la existencia de la República de Colombia también procedieron a regenerar la facultad del Ejecutivo para objetar los proyectos de ley aprobados por las legislaturas, y tal como había preceptuado la tradición constitucional inaugurada en 1821, la nueva aprobación de las leyes o decretos objetados exigía en cada una de las dos cámaras una votación cualificada de las dos terceras partes para que el Ejecutivo fuese obligado a sancionar el proyecto objetado.

\section{Opciones históricas de la objeción de leyes por el Ejecutivo:}

El derecho de objeción de leyes aprobadas por las cámaras legislativas, concedido al Poder Ejecutivo por la primera constitución colombiana, tenía como finalidad interponer un segundo control, por fuera del Poder Judicial, a los despropósitos, imprudencias e insuficiencias de algunos legisladores temerarios. Así lo entendió el vicepresidente Santander y su Consejo de Gobierno, siempre atentos a revisar cuidadosamente todos los proyectos legislativos antes de estampar las firmas que los pondrían en ejecución:

Demasiado saben los representantes de la república los peligros a que exponen las leyes oscuras y vagas. No solo el pueblo está en riesgo de ser oprimido, sino que las autoridades están expuestas a ser juzgadas con injusticia. Las palabras vagas de la ley producen divergencia en el modo de entenderlas, y un juicio equivocado puede ser la sentencia de muerte o de ignominia para quien acaso no tiene otro delito que la poca capacidad de su entendimiento. Las leyes que dejan a las autoridades un juicio estimativo no son menos funestas, porque siendo inherente a nuestra fragilidad pensar y discurrir de diferente modo, y no acordarnos en nuestras ideas, es muy fácil que por la misma diferencia de juicio condenen unos lo que otros aprobarían ${ }^{16}$.

Un examen de buena parte de los proyectos de ley que fueron devueltos al Congreso con objeciones del Poder Ejecutivo, entre 1823 y 1840, muestra en perspectiva histórica las opciones posibles del Poder Legislativo ante las objeciones recibidas: archivar el proyecto aprobado, corregirlo para remitirlo a la siguiente legislatura, bien fuese acogiendo los argumentos del jefe del Ejecutivo o insistiendo en lo mismo con una mejor redacción, o simplemente desechar las objeciones e insistir en el proyecto original. En lo que sigue se mostrarán esas opciones con los ejemplos de proyectos históricamente objetados.

\section{Archivar los proyectos del Legislativo}

La legislatura de 1825 aprobó un decreto que concedía varias exenciones a los habitantes de la isla de Margarita, solicitadas por el subteniente Eduardo Flex, quien había sido enviado para tal efecto a Bogotá, entre ellas la liberación de su comercio, la introducción de presas de corsarios, la agregación al departamento de Venezuela y la prohibición de sacar reclutas de ella. Aunque los legisladores habían acogido y escuchado con benignidad al enviado de los margariteños, el vicepresidente objetó el decreto, juzgándolo "obra de la fuerza", y tronó contra el Congreso:

\footnotetext{
${ }^{16}$ Francisco de Paula Santander, "Comunicación dirigida al presidente de la Cámara de Representantes, Bogotá, 26 de enero de 1825”, en Cartas y mensajes del general Francisco de Paula Santander (Bogotá: Academia Colombiana de Historia, 1954), vol. v, 129.
} 
En vez de oír el Congreso las exposiciones del gobierno sobre estos sucesos violentos y descargar el rigor de la justicia contra una tropa insubordinada, contra oficiales sediciosos y autoridades turbulentas, expide un decreto concediendo lo mismo que Margarita ha resistido cumplir, a saber, la conscripción de sus habitantes. ¿Qué se podrá decir cuando de una parte se ve acusado y suspenso a un magistrado de orden judicial porque ha faltado a una ley, y de la otra se ve favorecido un pueblo que de un golpe las ha atropellado todas? ${ }^{17}$.

Esas exenciones no podían ser concedidas sin que hubiese precedido un "acto de escarmiento", porque serviría a todos de ejemplo de cómo un pueblo podía rebelarse contra las leyes para obtener del Congreso la exención de la conscripción para el ejército. Era tan escandalosa la pretensión de los margariteños, después de la rebelión armada que impidió el envío de cien reclutas hacia la campaña del Perú, que el vicepresidente protestó que no se responsabilizaría por mantener el orden público en la isla, quedando en ella guarniciones de sus propios habitantes, ni por las conmociones que hicieren otras provincias, "seducidas por el buen suceso que ha tenido la conmoción" producida entre julio y septiembre de 1824. Ante la dura postura del Ejecutivo, el Congreso decidió archivar el decreto objetado y abstenerse de dar respuesta a las demandas de los margariteños. Según el secretario del Interior, José Manuel Restrepo, tampoco el Poder Ejecutivo "juzgó político irritar a sus habitantes infligiendo castigos a los autores de aquella momentánea rebelión", si bien reconoció que no se habían cometido "excesos de insultos, robos ni asesinatos", lo cual manifestaba "las virtudes caprichosas de los margariteños" $"$.

La legislatura de 1825 aprobó el primero de mayo una ley que fijaba el tipo de la moneda de plata y de oro que debía circular en Colombia. Al abrirse la legislatura de 1826 la objetó el vicepresidente, argumentando que la ley aprobada había introducido una variación en la moneda de oro que había establecido el congreso constituyente, dado que no solamente había variado la posición de las dos cornucopias, sino además había ordenado añadir en los campos vacíos de la parte superior seis estrellas de cada lado, con forma circular, para que denotaran los doce departamentos que integraban la República.

La objeción se basó en la consideración del interés de los comerciantes nacionales al llegar al extranjero, pues la circulación de esas nuevas monedas podía ser detenida mientras se ensayaban, perdiendo su valor nominal por algún tiempo, como había sucedido con las primeras monedas que corrieron con el tipo colombiano. Mientras corrían los nuevos diseños, por 16 pesos las onzas, los comerciantes podían sufrir pérdidas considerables. Convenía entonces al interés nacional no introducir innovación alguna en el diseño de las monedas de oro. En cambio, valía más diferenciar por el tipo esa moneda respecto del peso fuerte de plata, y además los reales de plata respecto de los escudos de oro; para que así fuese bien notable la diferencia entre las monedas de oro y las de plata, y así se evitara el fraude por medio de la técnica del dorado de estas. Cuando el Ejecutivo había solicitado al Congreso que fijara algunas diferencias entre el tipo de las monedas de oro y de plata, no había pretendido que se variase el tipo que tenía la de oro ${ }^{19}$. Vistos

\footnotetext{
${ }^{17}$ Francisco de Paula Santander, "Comunicación dirigida al presidente de la Cámara de Representantes, Bogotá, 29 de marzo de 1825”, en Cartas y mensajes del general Francisco de Paula Santander (Bogotá: Academia Colombiana de Historia, 1954), vol. v, 225.

18 José Manuel Restrepo relató en su Historia de la República de Colombia en la América Meridional (1827) los hechos facciosos de los habitantes de la isla de Margarita, quienes se opusieron al envío de reclutas hacia Cumaná para su posterior remisión al Perú. Edición académica de Leticia Bernal (Medellín: Universidad de Antioquia, 2009), vol. II, 366-367.

19 "Parte no oficial", Gaceta de Colombia, 209 (16 de octubre de 1825), 2-3. Francisco de Paula Santander, "Comunicación dirigida al presidente de la Cámara de Representantes, Bogotá, 3 de enero de 1826”, en
} 
los reparos del Ejecutivo no insistió la Cámara de Representantes y archivó el proyecto. Como consecuencia también fue archivado el proyecto de ley que ordenaba la amortización de la moneda llamada macuquina y su reacuñación como moneda de cordoncillo, con otra ley de metal, también objetada por el Ejecutivo ante la legislatura de 1825 , por ser un proyecto íntimamente ligado al anterior y que tenía que suspenderse al mismo tiempo que fue suspendido aquel, "porque sería imposible verificar la reacuñación sin saberse cuál era la empresa que debía ponerse a las nuevas monedas de plata" 20 .

Cuando las legislaturas aprobaban leyes que tenían implicaciones en el gasto del Ejecutivo, este tenía que objetarlas con el argumento de que los legisladores debían fijar el rubro fiscal que permitiría cumplir con lo legislado. Así sucedió el 30 de abril de 1825, cuando las cámaras legislativas aprobaron una ley que autorizaba al gobierno para aumentar los sueldos de los servidores de la República. La objeción del vicepresidente Santander no se hizo esperar, fundada en el argumento de que el Congreso no había especificado el origen de los fondos públicos con los cuales se cubriría ese gasto:

Si los pequeños sueldos actuales se pagan a fuerza de afanes, ¿cómo se pagarían si se aumentasen? No hay quien ignore que si de las arcas nacionales se ha de sacar como para cuatro es preciso que antes entre en ellas en igual proporción.

Este proyecto fue devuelto de nuevo a la Cámara de Representantes el 3 de enero de 1826 con la siguiente objeción: "Careciendo el erario de fondos suficientes para pagar sus actuales asignaciones, menos podrá haberlo cuando estas se aumenten, sin que las leyes de hacienda hayan proporcionado hasta ahora incremento a las rentas" ${ }^{21}$. El vicepresidente sabía que los sueldos de los servidores del Estado eran muy bajos, y por ello eran muy frecuentes las renuncias, en cuanto podían estos encontraban en otros empleos una mayor remuneración. Su impacto en las rentas públicas recaudadas era la consecuencia, "ya por el poco celo que aplican a su aumento unos, distraídos en procurarse la subsistencia por otros medios, ya por los fraudes que pueden cometer otros, o por su connivencia comúnmente remunerada" ${ }^{22}$. Como el Ejecutivo no podía firmar el "ejecútese", naturalmente estos proyectos resultaban archivados.

Otro ejemplo fue el decreto aprobado por la legislatura de 1824 para ordenar la impresión de todas las leyes expedidas por las legislaturas de 1823 y 1824 en un solo volumen, que el Ejecutivo objetó el 4 de enero de 1825 por "falta de fondos para hacer tal gasto y porque no señaló de dónde se erogaría la suma necesaria". Dado que los dineros provenientes del empréstito inglés tenían "objetos determinados por la ley" y todos los días crecían los gastos que debían ser sufragados por los fondos comunes, era preciso objetar el decreto de la legislatura porque "no me parece conveniente sancionar leyes que no pueda cumplir". La impresión de las leyes y decretos eran absolutamente necesaria para mejorar la administración pública, pero para ello tenía el congreso que aplicar alguna cantidad efectiva para hacerlo ${ }^{23}$.

Cartas y mensajes del general Francisco de Paula Santander (Bogotá: Academia Colombiana de Historia, 1954), vol. VI, 18-19.

20 "Parte no oficial", Gaceta de Colombia, 209 (16 de octubre de 1825), 2-3.

21 "Parte no oficial", Gaceta de Colombia, 209 (16 de octubre de 1825), 2-3.

${ }^{22}$ Francisco de Paula Santander, "Comunicación dirigida al presidente de la Cámara de Representantes, Bogotá, 3 de enero de 1826", en Cartas y mensajes del general Francisco de Paula Santander (Bogotá: Academia Colombiana de Historia, 1954), vol. VI, 19-20.

${ }^{23}$ Francisco de Paula Santander, "Comunicación dirigida al presidente de la Cámara de Representantes, Bogotá, 4 de enero de 1825”, en Cartas y mensajes del general Francisco de Paula Santander (Bogotá: Academia Colombiana de Historia, 1954), vol. v, 77. 
También decidió la legislatura de 1827 archivar el proyecto de ley que acogía el primer Código Penal de la República, teniendo a la vista el gran número de objeciones que interpuso a sus artículos el vicepresidente. Aunque este sabía que la legislación penal española que se había mantenido vigente durante la experiencia colombiana era complicada y hacía depender la suerte de los reos de muchos caprichos de los jueces, quería un código penal propio que fuera tan claro que no dejase "lugar a interpretaciones y que no contenga penas que se hagan ilusorias por las graves dificultades que se presentan para ejecutarlas" 24 .

El proyecto de ley sobre cementerios, aprobado por la legislatura de 1827, también fue archivado a petición del vicepresidente Santander por razones de prudencia política: el conjunto de leyes que desde 1821 habían introducido muchas reformas a los cleros ${ }^{25}$ habían producido muchos descontentos y enemigos del gobierno republicano. Una ley más sobre secularización de los cementerios aumentaría el número de los descontentos en las ciudades, especialmente entre personas de influencia, porque las corporaciones de los dos cleros no dejarían tranquilamente que sus sepulcros no estuvieran en sus iglesias. Las monjas creerían violadas sus clausuras si se sacaban sus cadáveres de sus conventos. Era mejor suspender la ejecución de tal ley "para mejor ocasión”, o al menos suavizarla respecto de las monjas, los frailes regulares y otras corporaciones eclesiásticas que tuviesen bóvedas o panteones en sus iglesias ${ }^{26}$. Esta condescendencia de un liberal moderado con los eclesiásticos seculares y regulares contrastó con el decreto que el 15 de octubre de 1827 dio el Libertador presidente para ordenar que desde ese mismo mes debían enterrarse todos los muertos en cementerios públicos, sin excepción de estado, condición o sexo, tal como estaba ordenado en la real cédula española que se convirtió en la Ley $2^{\mathrm{a}}$ del título $3^{\mathrm{a}}$, libro primero del apéndice a la Novísima Recopilación de las leyes de Indias $^{27}$.

\section{¿Aceptar o desechar las objeciones del Ejecutivo?}

Las cámaras legislativas dieron un ejemplo de la opción de aceptación de todas las objeciones presentadas por el Poder Ejecutivo con ocasión de la ley que declaraba abolido el cobro de las medias anatas, anualidades y mesadas eclesiásticas que pesaban sobre los eclesiásticos diocesanos desde los tiempos indianos, aprobada por la legislatura de 1825. El vicepresidente Santander la objetó no solo para ilustrar a los congresistas sobre las tradiciones históricas de la situación fiscal del clero, sino para extender los beneficios de la ley a todos los empleados públicos. Bajo la administración monárquica todo empleado civil o eclesiástico debía pagar el impuesto de media anata antes de posesionarse en cualquier oficio, como tenía que pagar la mesada eclesiástica todo religioso que lo hiciera en un oficio de la Iglesia, un gravamen introducido por la Corona. Como esta ley descargaba a los eclesiásticos colombianos de esas contribuciones fiscales, Santander pidió la inclusión de todos los empleados públicos en ese beneficio,

\footnotetext{
${ }^{24}$ Francisco de Paula Santander, "Comunicación dirigida al presidente del Senado, Bogotá, 28 de marzo de 1827”, en Cartas y mensajes del general Francisco de Paula Santander (Bogotá: Academia Colombiana de Historia, 1954), vol. VII, 95-109.

${ }^{25}$ Entre esas reformas se contaban la supresión de conventos que en 1821 no tuvieran ocho religiosos, la prohibición de profesar religión regular antes de los 25 años y la aplicación de las rentas de algunas prebendas vacantes al crédito público.

${ }^{26}$ Francisco de Paula Santander, "Comunicación dirigida al presidente de la Cámara de Representantes, Bogotá, 29 de marzo de 1827, en Cartas y mensajes del general Francisco de Paula Santander, (Bogotá: Academia Colombiana de Historia, 1954), vol. VII, 109-111.

${ }^{27}$ Decreto del 15 de octubre de 1827, dado por el Libertador presidente, en el que ordena enterrar todos los muertos en cementerios públicos y no en templos o capillas, Bogotá. Decreto del 15 de octubre de 1827, en Codificación Nacional (Bogotá: Imprenta Nacional, 1926), tomo VII, 490-492.
} 
convencido de que "la disposición debe comprender a todos, sean de la profesión y clase que fuesen, pues no hay razón para privilegiar a unos contra el derecho de otros". Era de justicia abolir el cobro de la media anata a todos los empleados públicos o eclesiásticos, u omitir el beneficio ofrecido al clero ${ }^{28}$. Pero además el vicepresidente pidió mantener el cobro de esos gravámenes eclesiásticos hasta el día en que fuese sancionada la ley, para no generar dudas o interpretaciones variadas que embarazaran su administración. En esta oportunidad el Congreso acogió todas las objeciones del vicepresidente y modificó el primer artículo de la ley que fue finalmente sancionada con satisfacción de todos los argumentos del Ejecutivo ${ }^{29}$.

Otro caso de aceptación de las objeciones del Ejecutivo ocurrió cuando la legislatura de 1825 aprobó un decreto declarando que la ilegitimidad del nacimiento no era impedimento para obtener grados en las universidades ni para recibirse de abogados. El vicepresidente objetó la parte motiva por razones de conveniencia nacional, dado que juzgó que daría una mala impresión entre las naciones extranjeras la moralidad del pueblo colombiano, donde abundaban tanto los hijos ilegítimos. Para conjurar esa "impresión perjudicial”, recomendó redactar la ley en términos escuetos, fundándose solamente en el artículo 178 de la Constitución y en la indicación que para esos efectos no hacía falta ninguna información de legitimidad del nacimiento. Efectivamente, la ley que fue sancionada el 18 de abril de 1825 solo tuvo un considerando en la parte motiva y una escueta resolución: "Para obtener grados en las universidades y recibirse de abogados en la República no es un impedimento la ilegitimidad" 30 .

No ocurrió lo mismo en el caso de un decreto de restablecimiento del orden público que fue objetado, ligado a las medidas extraordinarias que había tomado el vicepresidente para enfrentar el reto político bautizado como "La Cosiata", la rebelión del general Páez contra una orden del Congreso, que lo llamó a dar explicaciones por un exceso de fuerza en una jornada caraqueña de reclutamiento de milicias. Como se recuerda, el 27 de abril de 1826 se produjo en Valencia una conmoción armada que puso al departamento de Venezuela al borde su separación de la autoridad soberana de la República de Colombia. El vicepresidente del Poder Ejecutivo respondió a esa conmoción con las facultades que le concedía el artículo 128 de la Constitución, y dictó las medidas extraordinarias indispensables. Pudo actuar así porque en ese entonces no estaba reunido el Congreso, pero el mismo artículo rezaba que cuando este ya estuviese reunido tenía el Ejecutivo que contar con su acuerdo previo y consentimiento para dictar las medidas extraordinarias. El vicepresidente ya había experimentado el procedimiento de consulta a la legislatura de 1825 para la adopción de medidas extraordinarias con ocasión del ataque armado al cuartel de Petare, en la madrugada del 8 de diciembre de 1824, convencido de la existencia de "un partido contra las instituciones y el régimen actual" en Caracas, pues

\footnotetext{
${ }^{28}$ Francisco de Paula Santander, "Comunicación dirigida al presidente de la Cámara de Representantes, Bogotá, 12 de marzo de 1825”, en Cartas y mensajes del general Francisco de Paula Santander (Bogotá: Academia Colombiana de Historia, 1954), vol. v, 195-196.

${ }^{29} \mathrm{El}$ texto del artículo $1^{\circ}$ de la Ley del 28 de marzo de 1825 quedó tal como lo pidió el vicepresidente: "La exacción de media annata y la de mesada eclesiástica con que hasta ahora ha sido gravado el sueldo y la renta de los empleados eclesiásticos, civiles y de hacienda no se causará en lo sucesivo desde la publicación de esta ley en la capital de la República, pero serán recaudadas y cobradas las medias annatas y mesadas eclesiásticas devengadas hasta la fecha en que se haga dicha publicación”. Gaceta de Colombia, 186 (8 de mayo de 1825).

${ }^{30}$ Francisco de Paula Santander, "Comunicación dirigida al presidente de la Cámara de Representantes, Bogotá, 29 de marzo de 1825”, en Cartas y mensajes del general Francisco de Paula Santander (Bogotá: Academia Colombiana de Historia, 1954), vol. v, 223-224. El decreto del Congreso solo consideró que era "un deber de la nación proteger todos los colombianos a quienes por su parte no puede prohibírseles cualquier género de trabajo o industria conforme al artículo 178 de la constitución". Gaceta de Colombia, 187 (15 de mayo de 1825), 1.
} 
"la fama pública" decía que reunía tanto a "patriotas reconocidos" como a "hombres absolutamente desafectos"31.

Durante el siguiente año, el 7 de junio de 1827, la legislatura aprobó un decreto dirigido a restablecer el orden político, cuyo primer artículo decía que estando ya reunido el Congreso cesaban las facultades extraordinarias que estaba ejerciendo el vicepresidente. Este lo objetó sobre la base de una interpretación del artículo 128 constitucional, argumentando que la reunión del Congreso no suspendía el derecho del Ejecutivo para dictar medidas extraordinarias, sino que solamente lo obligaba a obtener su consentimiento para dictarlas. Como además el decreto hablaba del restablecimiento del "orden legal" anterior, quedaban en riesgo de abrogación las disposiciones que hasta entonces había dictado el Ejecutivo para conjurar la crisis política de 1826, dirigidas a mejorar la administración y a hacer ahorros en las rentas públicas ${ }^{32}$.

Una comisión del Senado, integrada por Francisco Soto y Alejandro Osorio, tuvo que estudiar las objeciones del Poder Ejecutivo al proyecto de ley mencionado. Esta sostuvo contra la opinión del vicepresidente que desde el momento en que se reunió el Congreso habían cesado sus facultades extraordinarias. No obstante, reconoció que las disposiciones adoptadas al amparo de las facultades extraordinarias no podían ser abrogadas súbitamente, pero el Ejecutivo tenía que restablecer progresivamente el orden político. Al restablecer el orden político que existía antes del movimiento de La Cosiata, el Congreso declaró entonces que desde el momento en que estuviese reunido ya el Poder Ejecutivo no podía dictar medidas extraordinarias sin previo acuerdo y consentimiento del mismo Congreso, ratificando el espíritu del artículo 128 de la Constitución. Hecha estas modificaciones al proyecto original, procedió el vicepresidente a firmar su sanción el 20 de junio de 1827. Para que en adelante quedara firmemente establecido el control del Congreso sobre cualquier "medida extraordinaria" dada por el Ejecutivo, desbordado "la esfera natural de sus atribuciones", se agregó en esta ley un cuarto artículo que advertía a los colombianos que no estaban obligados a obedecer "sino a las autoridades establecidas por los medios y en la forma que prescribe la constitución, o la ley" ${ }^{3}$.

Un caso de desconfianza entre los dos Poderes lo propició la legislatura de 1825 cuando aprobó un decreto que autorizaba al Ejecutivo para fijar el uniforme y las divisas del Ejército colombiano, pero reservándole al Congreso la facultad para aprobar o reformar cualquier decisión que hiciera el Ejecutivo en este asunto. El vicepresidente Santander lo objetó porque le parecía que no debía ejecutar la autorización concedida en esos términos, en consideración a que una vez realizados los costos del uniforme señalado por el Ejército podría suceder que anualmente cada legislatura quisiera reformarlo, "causando un enorme perjuicio a los militares, cuyo sueldo no sufre estas variaciones anuales". Pero además el vicepresidente consideró que la reserva hecha por el Congreso en este asunto suponía "poca confianza de que el Ejecutivo desempeñara satisfactoriamente una autorización tan sencilla, que es una de las facultades que la ley

\footnotetext{
${ }^{31}$ Francisco de Paula Santander, "Comunicación dirigida al presidente del Senado, Bogotá, 28 de enero de 1825”, en Cartas y mensajes del general Francisco de Paula Santander, (Bogotá: Academia Colombiana de Historia, 1954), vol. v, 133.

32 "Objeciones del vicepresidente del Poder Ejecutivo de Colombia a un decreto de restablecimiento del orden político dado por el Congreso, 9 de junio de 1827”, Gaceta de Colombia, 297, suplemento (24 de junio de 1827), 5-6.

${ }^{33}$ Informe de la comisión del Senado formada para examinar las objeciones del Ejecutivo interpuestas al proyecto de ley sobre el restablecimiento del orden político, 19 de julio de 1827, Gaceta de Colombia, 297, suplemento (24 de junio de 1827), 6-7. Decreto sobre el restablecimiento del orden político, aprobado por las dos cámaras legislativas el 19 de junio de 1827 y sancionado por el Ejecutivo el 20 de junio de 1827, Gaceta de Colombia, 298 (1º julio de 1827), 1.
} 
militar ha concedido ilimitadamente al presidente de los Estados Unidos del norte"34. La legislatura del 1826 aceptó las objeciones del vicepresidente y reformó el proyecto de ley, aprobándolo el 23 de enero de 1826 a satisfacción del Ejecutivo, que al siguiente día lo sancionó. Los uniformes y divisas del ejército y la marina los arreglaría el Ejecutivo libremente, aunque tratando de que fuesen sencillos y económicos y, en cuanto se pudiera, los mismos que ya estaban en uso ${ }^{35}$.

La ley del 11 de marzo de 1825 sobre régimen político y económico de los departamentos y las provincias fue sancionada a su pesar por el vicepresidente Santander, pese a sus objeciones, porque el Congreso insistió en sus posiciones y desechó una parte de las objeciones. Diez días después de la sanción todavía el vicepresidente se lamentaba de que el Congreso hubiera desechado sus objeciones sobre el contenido del artículo 42 de esa ley, juzgando que causaría "males irreparables a la república en el presente estado". Ese artículo prohibía a los gobernadores de las provincias ocupar al mismo tiempo la comandancia de armas, excepto en las plazas de armas amenazadas por el enemigo, y esto temporalmente y con la obligación de informar al Congreso sobre los motivos que habían obligado a tal fusión de los mandos político y militar. Juzgando la resistencia del Congreso a permitirlo, declaró que le afligía "la idea de que, por querer aplicar los extremos de los principios liberales en la división del mando, vaya la república a experimentar un retroceso de perniciosas consecuencias". Su experiencia le había convencido de que era imposible "ocurrir a la defensa del país ni a su tranquilidad en las circunstancias presentes manteniendo divididos los mandos superiores político y militar de los departamentos", en especial su se tenía en cuenta que los ingresos nacionales eran inferiores a los egresos ${ }^{36}$.

En la disyuntiva entre ahorro fiscal y principio liberal de separación de funciones, esta vez se impuso el criterio liberal de los legisladores. Con la experiencia el vicepresidente aprendió los riesgos políticos de empoderar a los intendentes con el mando de las armas. Cuando la legislatura de 1826 aprobó la ley adicional a la mencionada ley orgánica del régimen político de los departamentos y las provincias, sus objeciones ${ }^{37}$ al primer artículo se dirigieron a la idea de que todos los funcionarios públicos de un departamento estaban subordinados a los intendentes. En su nueva opinión ya los militares no podían estar bajo el mando de los intendentes, dado que debían obediencia a sus comandantes. Fue entonces cuando tuvo que recordar que el artículo 151 de la Constitución solo había conferido a los intendentes el mando político de los departamentos, pero en los asuntos militares su intervención se limitaba al suministro de bagajes, alojamientos, subsistencias y pagas de prest.

En consecuencia, la dirección de la fuerza armada solo podía depender del jefe del Poder Ejecutivo, porque "la fuerza armada no puede depender, ni recibir órdenes, sino de una sola mano". Esa unidad del mando militar era indispensable para darle organización y dirección a la fuerza armada, "para consultar el secreto, alma de la movilidad del ejército y para aligerar cualquiera operación militar". Como era un

\footnotetext{
34 "Parte no oficial", Gaceta de Colombia, 209 (16 de octubre de 1825), 2-3. Francisco de Paula Santander, "Comunicación dirigida al presidente de la Cámara de Representantes, Bogotá, 5 de enero de 1826”, en Cartas y mensajes del general Francisco de Paula Santander (Bogotá: Academia Colombiana de Historia, 1954), vol. VI, 21-22.

35 "Ley autorizando al poder ejecutivo para arreglar el uniforme militar, Bogotá, 24 de enero de 1826", Gaceta de Colombia, 226 (12 de febrero de 1826), 1.

${ }^{36}$ Francisco de Paula Santander, "Comunicación al presidente de la Cámara de Representantes, Bogotá, 21 de marzo de 1825", Cartas y mensajes del general Francisco de Paula Santander (Bogotá: Academia Colombiana de Historia, 1954), vol. v, 208-209.

37 “Objeción del Poder Ejecutivo al proyecto de ley adicional sobre régimen político de los departamentos, 4 de abril de 1826”, Gaceta de Colombia, 267-268 (26 de noviembre y 3 de diciembre de 1826).
} 
principio de los Estados que la dirección de la fuerza armada era indivisible, nadie distinto al Gobierno supremo podía tener parte en ella porque el mando exclusivo del Poder Ejecutivo era la garantía de la seguridad exterior e interior. En cada departamento solo los comandantes generales podían tener el mando de las tropas en casos de urgencia, por ser personas que conocían el arte de la guerra, bien por estudio o bien por una larga práctica. Su idea era que los intendentes fuesen personas ajenas a la profesión militar.

Paradójicamente, en este momento criticó la idea de algunos legisladores según la cual en los departamentos ninguna autoridad debería escapar a la autoridad de los intendentes, llamando a matizarla con el reconocimiento de la dirección militar única. Por ello propuso agregar un parágrafo al primer artículo de esa ley que dijera:

Las leyes y decretos del Poder Ejecutivo se comunicarán a todas las autoridades de un departamento por conducto del intendente... pero las órdenes del poder ejecutivo a las autoridades militares se comunicarán a los comandantes generales, o a otra autoridad subalterna, según la exigencia del caso y juicio del mismo gobierno.

Esta nueva previsión del vicepresidente ya tenía en cuenta la experiencia de los tres departamentos del sur de Colombia, donde el Libertador presidente estaba uniendo en un solo general de la República el mando político de los intendentes y el mando militar de los comandantes generales. Esa tendencia, como se vio en la crisis de 1830, dio a los oficiales más cercanos al Libertador el poder necesario para las secesiones departamentales que pusieron fin a la experiencia de la República de Colombia.

Otro caso en el que la legislatura hizo caso omiso de las objeciones del Ejecutivo ocurrió cuando el vicepresidente Santander expresó una inconformidad con el proyecto de ley aprobado el 12 de abril de 1826, adicional a la Ley del 23 de junio de 1824 sobre división territorial. Dado que el primer artículo cambiaba los antiguos nombres de los departamentos de Orinoco, en adelante llamado Maturín, y del Apure, en adelante llamado Orinoco, preguntó: ¿Para qué variar los nombres de esos departamentos? Durante seis años se habían usado los nombres antiguos, "los pueblos y las autoridades se han acostumbrado a él, y la geografía colombiana lo había reconocido así y lo había trasmitido a la geografía general y a la historia". Esa variación sin necesidad significaba "destruir las memorias y anunciar una versatilidad que refluye contra el honor nacional"38. La legislatura de 1826 se encogió de hombros y el Ejecutivo debió sancionar el proyecto original.

Desde la primera legislatura constitucional de 1823, el vicepresidente Santander siguió de cerca las sesiones para informar al Libertador presidente sobre el rendimiento del trabajo legislativo y sobre la influencia que ejercía "el partido" favorable a las propuestas del ejecutivo. Su primer informe fue pesimista, pues pasados los primeros 60 días de sesiones "nada ha hecho" el Congreso. La mayoría de los senadores habían sido imparciales con respecto al gobierno, excepto Antonio Nariño y José Miguel Uribe, opositores a la administración de Santander. La mayoría de ellos tenía ideas liberales, excepto el obispo Rafael Lasso de la Vega, Antonio Malo y Vicente Lucio Cabal. El general Rafael Urdaneta había presidido bien el Senado, llevando los debates "con mucho decoro y sin animosidades". En cambio, la situación en la Cámara era distinta: aunque "el partido nuestro es fuerte y no piensan sino en cosas nuestras", poco adelantaban en los proyectos de ley de organización de la hacienda pública y de la guerra, del pronunciamiento sobre el empréstito tomado por Francisco A. Zea y sobre la autorización para el nuevo empréstito. Poco decoro observaban en los debates y "muchas veces se han levantado las sesiones por evitar animosidades y disturbios". Para colmo, se habían

38 "Parte no oficial", Gaceta de Colombia, 238 (7 de mayo de 1826), 3. 
formado dos partidos de opinión muy pronunciados: el del valle, integrado por los diputados más jóvenes, amigos de "la libertad racional" y del ejecutivo, respetuosos de la Constitución $^{39}$; y el de la montaña, mayoritariamente federalistas (enemigos de la Constitución de 1821) y enemigos del gobierno, "muy adheridos a las preocupaciones religiosas y animados del espíritu de provincialismo" "40.

El sentimiento partidista también impregnaba al Senado, pues el senador venezolano Luis Baralt protestó al comienzo de las sesiones de esta legislatura el mensaje de felicitación que les había dirigido el Libertador presidente con ocasión de la apertura del primer congreso constitucional, porque en él afirmaba que mantendría su promesa de morir con la espada en la mano, y a la cabeza del ejército de Colombia, antes que "permitir que se huelle el pacto de unión que ha presentado una nación al mundo, compuesta de Venezuela y Nueva Granada”. Este senador argumentó que esta expresión era un recelo del Libertador contra miembros de esta legislatura, a quienes suponía partidarios de las propuestas que difundían los redactores de los periódicos El Venezolano, El Insurgente y otros más que "preparaban la opinión pública para la federación”, con lo cual agraviaba notoriamente al Legislativo con "semejante desconfianza". Hubo necesidad de someter a votación la moción de censura por "la amenaza excesiva que envuelven las expresiones" del Libertador, apoyada por los senadores José María Vallarino, Manuel María Hurtado y Antonio María Briceño, pero gracias a la defensa que hicieron los senadores Francisco Soto y José Miguel Uribe de la "buena disposición del Libertador" resultó negada ${ }^{41}$.

\section{Solidaridad de los dos poderes}

Con ocasión de un proyecto de ley aprobado por la legislatura de 1825 para descargar al clero del deber de pagar medias anatas, anualidades y mesada eclesiástica, unos impuestos que pesaban sobre esta corporación desde los remotos tiempos indianos, aprovechó en vicepresidente Santander las objeciones que envió al presidente de la Cámara de Representantes para cobrarse una cuenta pendiente con el Congreso:

Yo he reparado que en los decretos un poco odiosos, como empréstitos, contribuciones o reclutamientos, que se han expedido a solicitud del Gobierno, empiezan dichos decretos con la fórmula de "vista la consulta o las comunicaciones del poder ejecutivo", y en los decretos favorables al pueblo o a una corporación no se usa de dicha fórmula. Bien verá el Congreso que

\footnotetext{
${ }^{39}$ Eran miembros del partido del valle el presidente de la Cámara (Domingo Caicedo), Juan José Osío (“ambiguo"), Manuel Pardo, José Joaquín Suárez, el presbítero Sotomayor, Jacinto María Ramírez, José Francisco Pereira, Rafael y Pedro (los dos Mosqueras), Pedro de Herrera, Cayetano Arvelo, Antonio Torres, Manuel María Quijano, Felipe Delepiani, Miguel Palacios, José Manuel Olivares, el presbítero Lorenzo Santander, el presbítero José Antonio Mendoza, Manuel Romo, Mauricio José Romero, Juan de Dios Picón, Ramón Miño, Ignacio Saravia, Juan Nepomuceno Azuero, José María Sanguineto, Isidro Arroyo, Juan Manuel Arrubla, Francisco Montoya, Juan de Dios Aranzazu, Leandro Egea, Ignacio Vanegas y el doctor Manuel Campos.

${ }^{40}$ Eran miembros del partido de la montaña el tuso Ignacio de Herrera, José Ignacio Sanmiguel, Antonio Viana, Juan Bautista Valencia, José Joaquín Ortiz, Manuel Baños, José Joaquín Chiriboga, José Guerrero, José María Hinestrosa, José Camilo Manrique, Juan Nepomuceno Escobar (el cura de Guateque), el presbítero Manuel J. Vásquez, José Antonio Marcos, Manuel José Escobar, el presbítero José María Arias, Miguel Valenzuela ("godo de Bucaramanga") y Mariano de Echezuría. Francisco de Paula Santander, "Cuadro político del Senado y la Cámara de 1823, en Comunicación dirigida al Libertador presidente, Bogotá, 6 de junio de 1823”, Cartas y mensajes del general Francisco de Paula Santander, comp. por Roberto Cortázar (Bogotá: Academia Colombiana de Historia, 1954), vol. IV, 172.

${ }^{41}$ Simón Bolivar, "Mensaje del Libertador presidente al presidente del Congreso, Tulcán, 31 de diciembre de 1822", en Obras completas, comp. por Gerardo Rivas Moreno (Bogotá, FICA, 2008), 47. Acta de la sesión del Senado del 15 de abril de 1823, en Fundación para la conmemoración del bicentenario del natalicio de Santander. Santander y el Congreso de 1823. Actas y correspondencia del Senado, 1989, tomo I, 31-33.
} 
es preciso que quien lleva la parte odiosa lleve también la favorables, y no es justo que se cargue al Ejecutivo solo lo primero ${ }^{42}$.

Esta demanda de "regularidad y justicia" que hizo el jefe del Ejecutivo al presidente de la Cámara de Representantes habla del ideal de solidaridad que los constituyentes de Colombia esperaban de los tres poderes públicos. Ese espíritu de solidaridad, en algunos casos, rayó en la complicidad cuando se forzó la letra de algunos artículos de la Constitución para cosechar frutos políticos que algunas circunstancias demandaban con urgencia. Por lo menos en dos ocasiones se produjo esta especial complicidad de los dos poderes: en la determinación del tiempo de la primera Administración del Ejecutivo (1821-1827) y en el malabarismo constitucional que hizo posible la convocatoria a la gran Convención de Ocaña, como se detallará enseguida.

Como el artículo 107 de la Constitución colombiana fijó en cuatro años la duración del presidente de la República en su empleo, la legislatura de 1824 planteó un problema que ofrecía algunas dudas: ¿cuál era el día exacto en el que terminaban sus mandatos tanto el primer presidente constitucional como su vicepresidente? La Gaceta de Colombia había registrado el día en el cual el Congreso había elegido a estos dos altos funcionarios del Ejecutivo ( 7 de septiembre de 1821), como también los días en los cuales se habían posesionado en sus respectivos empleos tanto el primer presidente constitucional ( $1^{\circ}$ de octubre de 1821$)$ como su vicepresidente (3 de octubre de 1821$)$. Si se cumplía al pie de la letra el artículo 107 constitucional, sus mandatos debían terminar el 30 de septiembre de 1825, tras cuatro años exactos contados desde la posesión del Libertador presidente en su mandato estrictamente constitucional, y por voluntad de los constituyentes de la Villa del Rosario que lo habían elegido.

Pero el proyecto de ley que fijaba el día desde el cual comenzaban a contarse los cuatro años de ejercicio del presidente y vicepresidente en sus empleos fue objetado por el vicepresidente Santander. Su interpretación se basó en el texto de los artículos 72, 73 y 74 de la Constitución que determinaban el procedimiento para elegir al presidente, pues se requerían las dos terceras partes de los votos emitidos por los electores que concurrieran a las asambleas provinciales y, en caso de que esto no ocurriera, sería el Congreso quien perfeccionaría la elección. Para ello votaría solo por los tres candidatos que hubieran obtenido el mayor número de votos y ganaría el que obtuviera la mayoría cualificada. Si ninguno de ellos la obtuviera, se reduciría la votación a los dos que hubieran obtenido el mayor número de votos en el acto antecedente.

Como este procedimiento constitucional no se había realizado en el caso del primer presidente y vicepresidente del Ejecutivo, porque había sido el congreso constituyente quien, de una manera extraordinaria los había elegido, el tiempo transcurrido hasta el 2 de enero de 1823, día en que se debió reunir legalmente el primer congreso constitucional y comenzar el cómputo de los cuatro años, tendría que considerarse como tiempo extraordinario no válido. Este galimatías se agravaba con el hecho de que el primer senado constitucional realmente solo puedo instalarse el 8 de abril de 1823, y la primera Cámara de Representantes hasta el día siguiente. Prudentemente, la legislatura de 1824 no insistió en su proyecto y remitió este asunto a la siguiente legislatura.

La legislatura de 1825 efectivamente se ocupó del tema y, acogiendo la objeción del vicepresidente, aprobó el $1^{\circ}$ de mayo de este año la ley que decretó que el cuatrienio

\footnotetext{
${ }^{42}$ Francisco de Paula Santander, "Comunicación dirigida al presidente de la Cámara de Representantes, Bogotá, 12 de marzo de 1825”, en Cartas y mensajes del general Francisco de Paula Santander (Bogotá: Academia Colombiana de Historia, 1954), vol. v, 196-197.
} 
del primer presidente y vicepresidente de Colombia correrían desde el 2 de enero de 1823, por ser este año aquel "en que el congreso debe declarar las personas que resulten nombradas para dichos destinos según lo prevenido en los artículos 72, 73 y 74 de la Constitución"43. Como los mandatos de los generales Bolívar y Santander solo terminarían al mediodía del 2 de enero de 1827, resulta que ejercieron sus empleos durante un lapso de 459 días adicionales al cuatrienio prescrito por el artículo 107 de la Constitución.

Los constituyentes colombianos de 1821 establecieron con precisión en el artículo 191 de la Constitución que aprobaron en la Villa del Rosario de Cúcuta las condiciones para que otros constituyentes posteriores pudieran reformar la primera carta fundamental de la República de Colombia:

Artículo 191. Cuando ya libre toda o la mayor parte de aquel territorio de la República que hoy está bajo del poder español, pueda concurrir con sus representantes a perfeccionar el edificio de su felicidad, y después de una práctica de diez o más años haya descubierto todos los inconvenientes o ventajas de la presente Constitución, se convocará por el Congreso una Gran Convención de Colombia, autorizada para examinarla o reformarla en su totalidad.

Quedó entonces definido que antes del 30 de agosto de 1831 ninguna cámara legislativa colombiana podría convocar alguna convención constituyente. Pero tras la experiencia de la rebelión acaecida en Valencia en 1826, conocida como "La Cosiata", algunos publicistas comenzaron a asegurar que en nueve de los doce departamentos colombianos se escuchaban voces pidiendo una convención constituyente que remediara los supuestos errores administrativos del vicepresidente Francisco de Paula Santander, que explicarían "la insubordinación, la violencia y asonadas de la milicia". El Colibrí de Caracas, por ejemplo, en su primera entrega del sábado 9 de junio de 1827 dijo que había llegado "el momento de establecer sobre bases sólidas e inmutables las reglas fundamentales del pacto social que deba reunir para siempre la familia de los colombianos" en un momento en que era posible aprovechar la experiencia de...

...cinco años de penuria y aflicción bajo un gobierno que se decía central, sin vigor, republicano sin virtudes, representativo sin la concurrencia de los representantes de los departamentos, y popular son que se hubiesen consultado los intereses del pueblo, ni sus voluntades.

Cuando el Libertador presidente regresó del Perú prometió en Maracaibo a los venezolanos una convocatoria a colegios electorales para que estos declararan "cuándo, dónde y en qué términos quieran celebrar la gran convención nacional" ${ }^{4}$. Gracias a esta promesa fue que el general José Antonio Páez suspendió la vigencia de su decreto del 13 de diciembre de 1826 que convocaba una reunión de la representación del departamento de Venezuela en la ciudad de Valencia. El Patriota de Guayaquil aplaudió en su séptima

\footnotetext{
43 "Ley fijando la época en que deben comenzarse a contar los cuatro años de la duración del presidente y vicepresidente de la República, 2 de mayo de 1825”, Gaceta de Colombia, 191 (12 de junio de 1825), 1.

44 "Decreto del Libertador presidente poniendo los departamentos de Maturín, Venezuela, Orinoco y Zulia bajo sus órdenes inmediatas. Cuartel general de Maracaibo, 19 de diciembre de 1826", Gaceta de Colombia, 275 (21 de enero de 1827). El perjurio del Libertador es evidente si se recuerda que en el mensaje que dirigió al congreso constitucional de 1823 reiteró, por segunda vez, su promesa de "morir antes, la espada en la mano, a la cabeza del ejército de Colombia, que permitir que se huelle el pacto de unión que ha presentado una nación al mundo, compuesta de Venezuela y Nueva Granada. La constitución es sagrada por diez años: no se violará impunemente mientras mi sangre corra por mis venas y estén a mis órdenes los libertadores". Simón Bolivar, "Mensaje del Libertador presidente al presidente del Congreso, Tulcán, 31 de diciembre de 1822", Obras completas, compilación de Gerardo Rivas Moreno (Bogotá: FICA, 2008), 47.
} 
entrega, del 3 de febrero de 1827, el ofrecimiento de convención constituyente, imaginando que de ella saldrían "tres estados colombianos que, confederados al Perú y Bolivia, van a estrechar el lazo sagrado que detenga con una mano la santa alianza, y con la otra sostenga la igualdad legal y la verdadera libertad".

Sorpresivamente, las dos cámaras legislativas aprobaron el 25 de julio de 1827 un proyecto de ley que convocó a la gran convención constituyente, la cual abriría sus sesiones el 2 de marzo de 1828 en la ciudad de Ocaña. Como los legisladores no ignoraban el precepto constitucional del artículo 191, consideraron que "la afluencia y precipitación de los acontecimientos políticos", que habían ocurrido desde La Cosiata, ya habían arrojado "las lecciones de aquella experiencia que el congreso constituyente esperaban del trascurso de diez años". Como era de esperarse de un proyecto de ley que desconocía la letra de la constitución vigente, dos días después el vicepresidente Santander lo objetó.

El 28 de julio de 1827, el jefe encargado del Poder Ejecutivo expuso al presidente del Senado las razones de su negativa a sancionar el mencionado proyecto de ley: para empezar, era imposible anticipar la gran convención, "lisa y llanamente", antes de 1831, sin trasgredir ante los ojos de América y Europa el artículo 191 de la constitución vigente. Pero argumentó que existía una posibilidad de convocar la gran convención si se derivaba del artículo 189 que facultaba al Congreso para "resolver cualquier duda que ocurra sobre la inteligencia de algunos artículos" de la Constitución. Era preciso usar este recurso constitucional para resolver el problema político del día, originado en el peso de la persuasión que tenía el Libertador presidente respecto de que era toda la nación la que pedía anticipar la reunión de la gran convención, cuando una parte considerable de ella no la pedía. Para evitar exponer la suerte del país a "una guerra civil entre reformistas y constitucionales", era preciso ceder a esa pretensión intempestiva, solo porque "la prudencia y el bien nacional aconsejan ceder". Propuso entonces un nuevo texto para la resolución del proyecto de ley, que debía rezar como sigue:

El trascurso de los 10 o más años prefijados en el artículo 191 de la Constitución para que se convocara la gran convención, que debe ser reformada, debe ser un transcurso pacífico en que el entorpecimiento de la marcha del sistema y de la acción del gobierno no comprometa en manera alguna la suerte de la nación; mas no cuando las agitaciones puedan comprometerla como sucede al presente.

Este artilugio legal permitió convocar la gran convención y conjurar una probable guerra civil entre constitucionalistas y reformistas. Pese al ejercicio del derecho de objeción de un proyecto de ley aprobado en las cámaras legislativas, en este caso ocurrió que el vicepresidente encargado del Poder Ejecutivo cedió ante el Poder Legislativo porque sabía que este contaba con el respaldo del poderío del Libertador presidente en su propósito. Fue así como el 3 de agosto de 1827, el Congreso volvió a aprobar el proyecto de ley que convocó a la gran Convención de Ocaña, adoptando en sus resoluciones la sugerencia legal del vicepresidente, que quedó en su texto como sigue:

Artículo $1^{\circ}$. Aunque en el curso ordinario y regular de los acontecimientos habría sido necesaria la práctica de la constitución por diez o más años, que se exige en su artículo 191 para que el Congreso pudiera convocar la gran convención de Colombia; sin embargo en las críticas circunstancias en que se halla la República, la experiencia ya obtenida basta y llena el espíritu del artículo citado ${ }^{45}$.

Cuatro días después, el vicepresidente Santander y el secretario del Interior

\footnotetext{
${ }^{45}$ El proyecto de ley, la objeción legal del vicepresidente Santander y el texto definitivo de la ley que convocó la gran convención constituyente fueron publicadas en la Gaceta de Colombia, suplemento a la entrega 303 (5 agosto de 1827) y 304 (12 de agosto de 1827).
} 
firmaron este nuevo proyecto y el ejecútese, quedando sancionado como ley. El campo de la lucha política se había traslado a Ocaña, donde la "gran convención constituyente" que tantas expectativas despertó en todas las provincias, fracasaría estruendosamente ${ }^{46}$.

Pero esta solidaridad de los dos poderes para retorcer la letra de la Constitución, según "las críticas circunstancias", no podía quedarse sin recibir una "crítica republicana". Una de esas ocasiones fue durante las sesiones de la convención constituyente del Estado de la Nueva Granada, cuando el diputado Juan Nepomuceno Toscano opinó que, al general Obando, quien acababa de ser elegido vicepresidente, debía exigírsele el juramento de cumplir la Constitución "en cuanto sea exequible, probablemente en vista de las circunstancias en que se halla un extremo de la república". El diputado José Ignacio de Márquez, "juicioso orador y severo republicano", se levantó para combatir esa proposición: la "palabra mágica circunstancias" había sido pretexto para instaurar la dictadura del Libertador y sus facultades omnímodas, para romper la Constitución con actas tumultuarias y escandalosas, para convocar prematuramente la convención constituyente de Ocaña y para derrocar un gobierno legítimo. Se trataba entonces de "una palabra ominosa que había labrado al país su ruina e infelicidad, pues todos han querido ser emperadores cediendo al imperio de las circunstancias".

Ante esa experiencia colombiana, había que aprender que "el magistrado no debe separarse un ápice de la pauta que se le manda seguir, es preciso que perezca, que arda y se consuma en medio del incendio de las leyes, antes que violarlas y sobreponerse a ellas". Esa experiencia había enseñado que no era posible conceder facultades extraordinarias al ejecutivo para que observara la Constitución "en cuanto sea exequible, es decir, según lo permitan las circunstancias reales o imaginarias". Por ello, esta nueva convención constituyente nunca podría sancionar ese principio "anárquico y destructor de las garantías individuales, sea cual fuere la interpretación que se le dé, porque de todo puede abusarse su ejecución" ${ }^{77}$. No por nada fue que el doctor Márquez encabezó en distintos momentos de su fecunda vida republicana la jefatura de los tres poderes públicos de la Nueva Granada, una condición que lo hace persona única en la historia nacional ${ }^{48}$.

\section{Defensa de la majestad del Poder Ejecutivo}

La figura del intendente departamental fue una pieza clave de la gobernabilidad del Poder Ejecutivo en el extenso territorio de Colombia. Sujetos directamente al presidente, de quien eran "agentes naturales e inmediatos", eran nombrados por él entre personas de su entera confianza para períodos de tres años, pues se trataba de las poleas

\footnotetext{
46 Juan de Dios Aranzazu había pronosticado, desde la crisis de la Cosiata, la división de los políticos en los cuatro partidos de opinión que destrozarían a Colombia: "los federalistas, los monarquistas, los bolivianos y los que defienden la constitución de 1821". Advirtió también que la suerte del gobierno nacional dependería de lo que quisiera el Libertador presidente, "porque todavía entre nosotros son los hombres primero que los principios". De todos modos, la opinión internacional sobre esta "periclitante Republiqueta" no dejaría de criticar "nuestra incapacidad para gobernarnos como nación, si es al influjo de un magistrado ilustre, más bien que al ascendiente del espíritu público, a quien se deba la estabilidad de nuestro sistema". Juan de Dios Aranzazu, "Carta dirigida a Rufino Cuervo, Rionegro, 16 de octubre de 1826", en Epistolario del doctor Rufino Cuervo (1826-1840), ed. por Luis Augusto Cuervo (Bogotá: Academia Colombiana de Historia, 1918) (Biblioteca de Historia Nacional, vol. XXII), 12.

${ }^{47}$ La Dilijencia, Bogotá, 1 (27 de noviembre de 1831), 3-4. En BNC, fondo Pineda, 183, piezas 8 y 9.

${ }^{48}$ La estatua de bronce y de cuerpo entero de José Ignacio de Márquez que el poder judicial colombiano instaló en sus dos palacios de justicia, para rendirle un homenaje póstumo a su republicanismo, fue testigo de sus dos destrucciones en 1948 y en 1985. En esta última un proyectil de gran calibre separó la cabeza del cuerpo que, mutilado, adorna uno de los jardines del Museo Nacional de Colombia. El historiador Eduardo Malagón Bravo ha convocado a una restauración de esa estatua para borrar la huella de un trágico acontecimiento de la historia colombiana en el que el poder judicial perdió su cabeza, representada por el presidente de la Corte Suprema de Justicia.
} 
de la cual pendía la cadena de la autoridad ejecutiva que iba a los gobernadores de las provincias y a los jefes políticos de los cantones. Cuando la legislatura de 1827 aprobó el 4 de julio un proyecto de ley, originado en el Senado, que introducía el recurso de una lista de personas elegibles para los cargos de intendentes y gobernadores originada en las asambleas electorales de las provincias, obligando al presidente a escoger solo de ella, el vicepresidente Santander tuvo que objetarlo el 8 de julio siguiente. El argumento de los proponentes era el de listar personas que gozasen en las provincias un "buen concepto público", para mejorar su gobernabilidad entre los pueblos que tendrían bajo su responsabilidad. Aunque, con acuerdo y consentimiento del Senado, quedaba a salvo la facultad constitucional del Ejecutivo para nombrarlos, el Senado con esta ley quería procurar que los elegidos fueran "del agrado de los pueblos que han de gobernar" y que tuviesen un "aura popular".

Las objeciones del Ejecutivo fueron tanto constitucionales como políticas. Eran de orden constitucional porque se le expropiaba al presidente de su libre facultad para nombrar a sus agentes directos en los departamentos y provincias, pero también lo eran de orden político, pues se disminuían sus facultades y la acción del gobierno en el nombramiento de sus agentes, disminuyendo también su fuerza.

Fue entonces cuando el vicepresidente Santander recordó a las cámaras legislativas que algunos célebres políticos de Europa habían criticado la Constitución de Colombia porque habían registrado la debilidad del Poder Ejecutivo. Preguntó entonces: "¿Será útil debilitarle aun cuando desgraciadamente palpamos que se ha relajado la fuerza de las leyes y la moral de los pueblos?". Si el Ejecutivo era obligado a nombrar sus intendentes y funcionarios solo de las listas de las asambleas electorales de las provincias y resultara así una mala elección, la responsabilidad no sería del Ejecutivo, porque había sido obligado a escoger entre personas que no merecían su confianza. Por otro lado, esas asambleas podrían equivocarse y proponer personas incapaces de gobernar. El Poder Ejecutivo podría aceptar esas listas solo para instruirse a la hora de nombrar sus subalternos, pero sin perder su libertad absoluta para escoger. Puestas a debate las objeciones del Ejecutivo en el Senado, resultó que los senadores Vicente Azuero y Alejandro Osorio se sostuvieron en el proyecto, pero los senadores José Ignacio de Márquez, Luis Andrés Baralt y Santiago Arroyo accedieron a las objeciones. Puesto a votación, la mayoría del Senado estuvo por no seguir insistiendo en los ocho artículos objetados, pero dejaron constancia de la posición contraria los senadores Baralt, Azuero y Vallarino ${ }^{49}$.

El proyecto de ley orgánica del Poder Judicial, que fue aprobado por las dos cámaras legislativas en 1824, fue objetado por el Consejo de Gobierno y aplazado para las sesiones de la legislatura de 1825 por varias razones que el vicepresidente Santander expuso el 3 de enero de 1825 al presidente del Senado ${ }^{50}$. Una de ellas era la atribución concedida a la Alta Corte de Justicia para juzgar a los secretarios de estado, agentes diplomáticos y ministros de las cortes superiores de justicia en las causas que les siguieran sobre "responsabilidad en el mal desempeño de sus funciones". Si bien la Alta Corte podía juzgar a los secretarios del despacho ejecutivo en las causas criminales que se les

\footnotetext{
49 "Proyecto de ley modificando el procedimiento para elegir los intendentes y los gobernadores, objeciones del vicepresidente Santander y nuevo debate dado en el Senado el 9 y 10 de julio de 1827', Gaceta de Colombia, 301, suplemento (22 de julio de 1827), 5-6.

${ }^{50}$ Francisco de Paula Santander, "Comunicación al presidente del Senado, Bogotá, 3 de enero de 1825", en Cartas y mensajes del general Francisco de Paula Santander (Bogotá: Academia Colombiana de Historia, 1954), vol. v, 35-77. Las reformas a esta ley orgánica, finalmente sancionada el 11 de mayo de 1825, fueron introducidas por las dos cámaras de 1825 para resolver las objeciones de Santander: Archivo General de la Nación, serie Archivo Histórico Legislativo, Senado, 22, proyectos de ley pendientes, negados y mandados a archivar, f. 8-95.
} 
siguieran, no existían razones válidas para procesarlos por el supuesto mal desempeño en sus funciones porque la Constitución no les atribuyó responsabilidad alguna en los decretos que firmasen, ni en los acuerdos del Consejo de Gobierno. La única persona responsable de esos actos, constitucionalmente, era el titular del Poder Ejecutivo, ya que ellos cumplían sus órdenes. Siendo el Poder Ejecutivo independiente, no podía el Poder Judicial mezclarse en las atribuciones propias del primero. Esa supervigilancia del Judicial sobre los ministros del Ejecutivo era un traspaso de sus límites que no estaba dispuesto a permitir, "pues juzgo por uno de mis primeros deberes el sostener ilesa la constitución". La consecuencia de tal extralimitación era obvia, pues al adquirir el Poder Ejecutivo y sus secretarios muchos enemigos en el ejercicio de sus funciones, incluso entre el poder judicial, "apenas habría año en que no se les promoviesen dos o tres procesos por mal desempeño en el ejercicio de sus funciones ante los ministros de la alta corte". Como resultado, "los destinos de secretarios de estado, que son tan importantes para la marcha del poder ejecutivo, quedarían envilecidos y continuamente expuestos".

El Senado estimó...

... preciso y conveniente variar la disposición objetada, reservando exclusivamente al Ejecutivo la facultad de suspender a los empleados de quienes se trata, designando en la Alta Corte el tribunal que solo después de suspensos deba juzgarlos con arreglo al artículo 175 de la constitución ${ }^{51}$.

Efectivamente, el texto que finalmente quedó consignado en la ley orgánica sancionada el 11 de mayo de 1825, como atribución $5^{\text {a }}$ de la Alta Corte, decía: "Conocer en primera y segunda instancia, previa la suspensión decretada por el Poder Ejecutivo, de las causas de responsabilidad que por mal desempeño en el ejercicio de sus funciones se formen a los secretarios de estado, etc." 52 .

Cuando la legislatura de 1825 aprobó, el $1^{\circ}$ de mayo, un proyecto de ley orgánica de las milicias colombianas fue objetado por el vicepresidente Santander con unos argumentos que denunciaba la incompetencia de los legisladores en este asunto:

Es casi literalmente copiado de la ley expedida por las Cortes de España para la milicia local. Se ha querido crear en Colombia una sola milicia, pero se le ha aplicado el reglamento a que debía sujetarse la milicia local de España, que como todos saben, es muy distinta de la milicia activa. Por consiguiente se ha debido incurrir en anomalías peligrosas. En Colombia no hay un cuerpo intermedio entre el ejército permanente y la milicia nacional cívica o local. El proyecto en cuestión, reduciendo toda la milicia nacional a una sola, impone una transición fuerte de ciudadano, en ejercicio de todos los derechos, a soldado del ejército permanente. El amor a la carrera de las armas, la disciplina militar y la instrucción está muy distante de crearse en nuestra milicia, y no seríamos injustos si dijésemos que esta ley reduciría la milicia colombiana a un completo laberinto que ninguna utilidad produciría ${ }^{53}$.

Las objeciones del vicepresidente eran una demostración de su pericia en asuntos militares y de la incompetencia de los legisladores que habían redactado el proyecto. Juzgó que la idea de integrar una sola milicia con todos los colombianos comprendidos entre los 18 y 50 años podría servir para todo, "menos para tener soldados con que

${ }^{51}$ Comunicación del presidente del Senado al presidente de la Cámara de Representantes remitiendo el nuevo proyecto de ley orgánica del Poder Judicial, Bogotá, 19 de marzo de 1825, en AGN, serie Archivo Histórico Legislativo, Senado, 22, proyectos de ley pendientes, negados y mandados a archivar, f. 9.

52 "Ley orgánica del Poder Judicial, 11 de mayo de 1825", Codificación Nacional (Bogotá: Imprenta Nacional, 1924), tomo 2 (1825-1826), 123.

53 "Parte no oficial", Gaceta de Colombia, 209 (16 de octubre de 1825), 2-3. Francisco de Paula Santander, "Comunicación dirigida al presidente de la Cámara de Representantes, Bogotá, 5 de enero de 1826”, en Cartas y mensajes del general Francisco de Paula Santander (Bogotá: Academia Colombiana de Historia, 1954), vol. VI, 24-34. 
aumentar nuestras filas en el ejército de campaña". Los servicios que podrían prestar esta masa de milicianos eran muy pocos, porque la milicia "es naturalmente opuesta a toda operación que la aleje de sus hogares". El Ejecutivo solo podía creer en una milicia auxiliar y reglada del Ejército, integrada por varones entre los 18 y 35 años, considerada como ejército de reserva, paralela a otra milicia local, integrada por jóvenes de 14 a 18 y hombres de 35 a 50 años. La propuesta de disolver las milicias regladas que ya existían en Colombia, y que prestaban útiles servicios, era una disposición perjudicial. No le parecía una buena política "deshacer con un rasgo de pluma lo que ha costado algún trabajo organizar", si se tenía a la vista que en todas las provincias donde se había cumplido la ley del alistamiento de milicias no había un solo ciudadano que se hubiera quejado de que le trataban como a soldado del ejército permanente. Las comunicaciones del comandante general de Venezuela informaban que habían sido alistados hasta 26.000 milicianos en su departamento, a pesar de que en Caracas era donde se habían levantado clamores contra la providencia dictada por el Ejecutivo en ejecución de un decreto del congreso constituyente. La Ley Orgánica de la Milicia Nacional finalmente aprobada por el Congreso el 30 de marzo de 1826 acogió todas las objeciones del vicepresidente, en vez de una sola milicia formó dos: la auxiliar (varones de 18 a 35 años) y la cívica (varones de 14 a 18 y de 35 a 50 años) ${ }^{54}$.

Otro caso de incompetencia temática de los legisladores ocurrió cuando la legislatura de 1826 aprobó el $1^{\circ}$ de febrero una ley que declaraba a los religiosos prebendados que fuesen miembros del Congreso incluidos en el derecho a percibir dietas durante las sesiones, como los demás empleados civiles y militares. El 9 de febrero siguiente la objetó el vicepresidente porque en el primer artículo se afirmaba que la renta de diezmos era una de las rentas públicas. Tuvo que recordar a los legisladores que los diezmos no eran una de las rentas de la nación porque, como defendería cualquier obispo, la República solamente había heredado del Estado de la Monarquía el derecho a llevar dos novenos de la mitad de la masa de los diezmos. Recordó también que el "noveno de consolidación" que se sacaba del total de la masa de los diezmos se había aplicado en su origen a la extinción de los vales reales de España, y en los tiempos republicanos debía destinarse a la caja de amortización. El rubro eclesiástico llamado vacantes mayores, aunque podía ser usado por el gobierno para sus necesidades, estaba destinado a propósitos piadosos y no a los gastos comunes en tiempos ordinarios, "y tampoco pueden mirarse como una renta del Estado". Aunque los ciudadanos pagaban los diezmos con el consentimiento del Congreso, este rubro no era una renta del Estado porque desde su origen había sido aplicado al pago de las congruas sustentaciones de los párrocos, como también a las fábricas de iglesias y hospitales. En ese antiguo reparto de la masa de los diezmos solo le pertenecían al Estados dos novenos de la mitad de la masa, pues la cuarta arzobispal y la cuarta de los cabildos catedrales no salía del Tesoro Nacional, sino de la otra mitad de la masa de los diezmos ${ }^{55}$.

Cuando la legislatura de 1826 aprobó el 22 de marzo una ley adicional de supresión de conventos menores, el vicepresidente Santander la objetó porque, entre otras cosas, introducía equívocos con el mal uso de los tiempos verbales con que había sido redactada. Como el Congreso estaba obligado en este tema a obrar "conforme a los principios de la justicia e imponer silencio a los opuestos a la ley, que no son pocos"

54 “Ley orgánica de la Milicia Nacional, sancionada en Bogotá el 1 de abril de 1826”, Gaceta de Colombia, 240-suplemento (21 de mayo de 1826), 5-8.

55 "Comunicación del Poder Ejecutivo al presidente del Senado. Bogotá, 9 de febrero de 1826", Gaceta de Colombia, 229 (5 de marzo de 1826), 2.

56 "Objeción del Poder Ejecutivo al proyecto de ley sobre supresión de conventos", Gaceta de Colombia, 261 (15 de octubre de 1826), 3. En carta al presidente del Senado de 1825 ya había advertido el 
no podía esa ley tener efecto retroactivo respecto de lo que había ordenado la Ley del 28 de julio de 1821, aplicable solo a los conventos menores de ocho frailes en "el día de la sanción de ley". El equívoco podría obligar a dar una nueva ley sobre se tema para los departamentos que aún estaban dominados por los españoles en 1821, como los del sur y el Istmo. Sugirió en cambio ampliar los efectos de la ley para que el Gobierno pudiera rematar algunos de los conventos suprimidos, o aplicarlos a cuarteles u hospitales.

Ya en los tiempos del Estado de la Nueva Granada, cuando Santander era su primer presidente constitucional, al objetar el proyecto de ley orgánica de los tribunales de la república que había aprobado la legislatura de 1833 vertió duras críticas a la competencia profesional de los jueces de primera instancia, convencido de que "la magistratura granadina todavía no ha llegado a crearse una reputación de firmeza que diese todas las garantías posible, y sobre todo a la oscuridad de las leyes criminales y penales". Su experiencia personal en 23 años de vida republicana le había mostrado que entre los granadinos había más más inclinación a "relajar las penas por compasión, por debilidad o por relaciones que a hacerlas aplicar estrictamente a toda costa". El origen de esta tendencia creía encontrarla en la educación española que habían recibido los abogados granadinos, pues aprovechando la distancia inmensa que había existido respecto del gobierno peninsular, el centro del poder del Estado monárquico, no se había administrado la justicia por las leyes sino "por consideraciones particulares". En las causas criminales en las que resultaban complicadas "personas de categoría o de influencia en un partido", era casi seguro que sobrarían "quienes se interesen por su impunidad". En la Nueva Granada generalmente se creía que era "una obra de caridad recomendable salvar un delincuente", y por ello los testigos desfiguraban los hechos, los perjurios eran frecuentes, los defensores usaban su talento para atenuar la pena mediante la desfiguración de la ley y los jueces eran "compasivos o débiles".

Un buen ejemplo de la mala administración de la justicia criminal en primera instancia es la célebre causa de los conspiradores que, encabezados por el general español José Sardá, habían atentado contra su vida el 23 de julio de 1833. Como se sabía que la pena de muerte recaería sobre muchos de esos conspiradores, los letrados habían interpretado la ley de buena o mala fe, "el interés de la compasión" había ejercido su influencia, el "espíritu de partido" había hecho de las suyas, y la calificación de los reos acreedores a la pena de muerte había sido muy variable: 27 para el juez de primera instancia, 44 para el fiscal del tribunal superior y 46 para los jueces del este tribunal. Este voluminoso expediente de la causa de los conspiradores mostraba el frecuente recurso del perjurio, la notoria colusión de los acusados, la publicidad de las interpretaciones de los abogados, la diferencia de juicio entre el juez de hacienda y el tribunal. Solo la firmeza, integridad y luces de los conjueces había salvado esta causa. Ninguna causa de responsabilidad se había abierto en la vida republicana contra los jueces o tribunales que en los juicios criminales habían dejado de aplicar la ley penal vigente.

Era su experiencia personal de esa peculiar historia de la administración de justicia en la Nueva Granada la que le daba argumentos para objetar el artículo 128 de la ley de tribunales, porque estaba convencido de que la Nueva Granada no estaba preparada para recibir, sin riesgo, dos innovaciones: los juicios por jurados y el sufragio universal masculino directo. Aunque el juicio por jurados era "el establecimiento jurídico más conforme a la razón y a la libertad", aunque las elecciones directas eran las que mejor armonizaban con el gobierno representativo, en la Nueva Granada de ese momento este artículo no era una garantía favorable a la sociedad sino el riesgo a ser atacada "en el 
orden y seguridad públicos, y en la de los asociados"57.

La objeción de Santander a la ley que estableció el régimen político-territorial de la Nueva Granada, fruto de la legislatura de 1833, no solamente precisó la nomenclatura legal de los poblamientos, sino que además puso en duda que la sociedad granadina estuviera preparada para adoptar los consejos comunales. Advirtió a los legisladores que las palabras "pueblos" y "parroquias", propias del antiguo régimen indiano, ya no eran utilizables en los textos legales porque no hacían parte del "lenguaje de la constitución". Como el artículo 150 de la Constitución del Estado de la Nueva Granada solo reconocía en el territorio de la república las entidades llamadas provincias, cantones y distritos parroquiales, en el texto de esta ley no podían aparecer las palabras "pueblos" ni "parroquias", sino "distritos parroquiales". Las provincias contaban con sus cámaras provinciales y sus gobernadores, así como habría concejos municipales en las capitales de provincia y en las cabeceras cantonales con capacidad, a juicio de las cámaras de provincia, pero aún la sociedad granadina no estaba lista para contar con consejos comunales en los distritos parroquiales. Aunque era "una idea feliz" contar con estas corporaciones, porque una consideración teórica la hacía aparecer adecuadas para promover los intereses locales y fomentar las mejoras que demandaban las poblaciones, "no todo lo que parece excelente es adaptable", porque ese sistema requería de una "abundancia de hombres en quienes puedan recaer los nombramientos de vocales". Ante esta realidad social preguntó: “¿Cuántos de nuestros distritos parroquiales están en capacidad de suministrar, no digo el máximum de nueve vocales, pero ni aún el mínimum de tres?" Su respuesta fue:

Bien pocos en verdad, puesto que en muchos ni siquiera hay individuos a quienes nombrar de alcaldes. Recorriendo la lista de las atribuciones de los consejos comunales me convenzo más de lo impracticable del proyecto entre nosotros, al menos mientras dure la actual condición de nuestros pueblos. Por la menor parte sería menester que los miembros de estos consejos supiesen leer y escribir, y distritos hay entre nosotros en que se ignoran absolutamente esas artes... Pasado algún tiempo debemos prometernos que mejor educados los pueblos y más adelantados en la carrera de la civilización, estarán en aptitud de recibir con fruto este arreglo benéfico ${ }^{58}$.

Propuso entonces posponer para una época futura la introducción de los consejos comunales, según lo aconsejaran "la prudencia y la necesidad, y lo permitan las circunstancias locales”. Efectivamente, ante la Cámara de Representantes de 1841 presentó el diputado por la provincia del Socorro, Vicente Azuero Plata, un proyecto de ley que introducía los consejos comunales, sustentado en un alegato vigoroso:

Dondequiera que hay cierto grupo de hombres formando una parroquia, tan posible es que así como todos se han reunido para formarla, así también turne un pequeño número de ellos en reunirse para atender a los peculiares intereses de esta pequeña comunidad y para proveer a su común bienestar; y esto es lo que se llama consejo comunal. Si son idiotas, éste será el medio de que comiencen a civilizarse; si se objeta que hoy miran con indiferencia sus intereses comunales, respondo que esta falta no es tan verdadera, o por lo menos tan general como se pretende, y que además tal indiferencia nace de la misma imposibilidad en que están de administrarlos; confiéraseles el poder de dirigirlos, impóngaseles el deber de verificarlo, y entonces despertarán del entorpecimiento en que yacen; el deseo tan natural al hombre de mejorar su condición, les hablará enérgicamente. ¿O sostendríamos con algunos presuntuosos europeos y norteamericanos

\footnotetext{
${ }^{57}$ Francisco de Paula Santander, "Comunicación dirigida al presidente de la Cámara de Representantes, Bogotá, 12 de diciembre de 1833”, en Cartas y mensajes del general Francisco de Paula Santander, 1955, vol. VIII, 379-381.

${ }^{58}$ Francisco de Paula Santander, "Comunicación dirigida al presidente de la Cámara de Representantes, Bogotá, 23 de diciembre de 1833”, en Cartas y mensajes del general Francisco de Paula Santander, 1955, vol. VIII, 414-415.
} 
que el genio, el buen sentido y la libertad son la prerrogativa de ciertas razas privilegiadas? Yo jamás creeré en estos dogmas de la vanidad civilizada de ciertos pueblos, que en otros tiempos fueron tan bárbaros e idiotas como nuestros indígenas y como los africanos ${ }^{59}$.

El proyecto que presentó a esta legislatura de 1841 intentaba conceder a las provincias y a sus pueblos "cuantas prerrogativas, ventajas y facultades puedan serles necesarias para remover todo mal, para promover todo bien y para encaminarse desembarazadamente al más alto grado de prosperidad". Pero los constituyentes de 1843 no introdujeron innovación alguna en el régimen político-territorial. En cambio, los de 1853 sí que abrieron todas las posibilidades de reformas de las localidades al conceder a las provincias, por el artículo 48, "el poder constitucional bastante para disponer lo que juzgue conveniente a su organización, régimen y administración interior”. Como consecuencia, durante los dos años siguientes se aprobaron constituciones municipales en muchas cabeceras de cantón e incluso en aldeas tan pequeñas como Onzaga.

Cuando la legislatura de 1837 aprobó un decreto que derogó todas las disposiciones que habían estado vigentes desde los tiempos colombianos sobre los textos escolares usados en la enseñanza pública, dejando en plena libertad a los catedráticos para elegir los textos a su arbitrio, los legisladores liberales granadinos pudieron sentirse satisfechos de haber consagrado el principio de la libertad de enseñanza. Pero el presidente Santander objetó ese decreto, pese a que la experiencia personal le había enseñado con el caso de las obras de Jeremy Bentham, prohibidas durante la dictadura de Bolívar, hasta donde podía llegar la intromisión del Poder Ejecutivo en este tema.

Su objeción se amparó entonces en "el celo puro" que siempre lo había "animado en favor de la buena enseñanza pública", íntimamente convencido de que este asunto era tan importante para el Estado que no podía ser expuesto a perjuicios por "el arbitrio y tal vez el capricho de cada uno de los preceptores o institutores". Como la enseñanza ejercía "una influencia demasiado constante y eficaz en los destinos del país" no podía ser "abandonada al acaso" en el tema de "las doctrinas", pues entonces se introduciría "una espantosa anarquía" en las aulas de las universidades y colegios. Dos ejemplos fueron presentados para ilustrar su preocupación: si los catedráticos de jurisprudencia canónica enseñaban la doctrina de la infalibilidad del papa y su supremacía sobre todos los asuntos temporales, usando textos de los autores ultramontanos, saldrían abogados que en los bancos del congreso subvertirían las instituciones liberales que apenas estaban en embrión. Si los profesores de medicina recetaban a sus alumnos los mismos libros que les habían servido en su formación, obstaculizarían a los nuevos médicos el conocimiento de los portentosos avances de las ciencias, pues "lo que hoy estaba en boga viene a ser mañana rancio y diminuto".

Recordó que como la enseñanza pública era costeada con los dineros de la nación no podía ser expuesta a influencias perniciosas, dado que "el legislador granadino no puede menos sino querer que la educación pública sea homogénea y acorde con la marcha ilustrada del siglo y con los dogmas políticos y sociales que profesamos". Era entonces preciso adoptar medidas de precaución para que las sucesivas generaciones "beban en fuentes puras las doctrinas y reciban de profesores aptos los preceptos y los ejemplos que han de formar esa misma educación". En los países del mundo civilizado los Estados encargaban a corporaciones respetables y cuerpos directivos la selección de los textos y su variación, así como la selección de profesores para las facultades científicas o literarias,

\footnotetext{
59 Vicente Azuero Plata. Instituciones de gobierno local, Bogotá, 10 de mayo de 1840, Imprenta de José Antonio Cualla (folleto titulado Honorables representantes). Reimpreso por Guillermo Hernández de Alba y Fabio Lozano y Lozano (comps.), en Documentos sobre el doctor Vicente Azuero (Bogotá: Academia Colombiana de Historia, 1944), 350-363.
} 
pues no se entregaba a hombres incapaces la enseñanza, que debería tener un método debido para que la juventud adquiriese positivos conocimientos ${ }^{60}$. En esta ocasión la legislatura de 1837 acogió las objeciones del Ejecutivo y archivó el proyecto de decreto.

La Cámara de Representantes aprobó el 22 de marzo de 1836, por una mayoría de 29 votos contra 23, una declaración que señalaba que el Ejecutivo había actuado inconstitucionalmente en el modo como había celebrado con el ministro plenipotenciario de Venezuela, Santos Michelena, el reparto de la antigua deuda colombiana. Como se trataba de una declaración intempestiva, porque el Senado del año anterior había aprobado la convención entre la Nueva Granada y Venezuela para el reparto de esa deuda, el presidente consideró que "vilipendiaba" su autoridad, sospechosamente en una época de elecciones presidenciales. Después de cuatro años de ofrecer arreglar esa deuda de una manera amigable y de discutir en el Consejo de Gobierno las mejores opciones, no podía "sobrellevar la responsabilidad moral" que se desprendía de ese acto legislativo. Celoso del honor que había adquirido en 26 años de carrera pública, e "interesado en la honra del gobierno que presido", retó a los representantes a aplicar el artículo 57 de la Constitución, es decir, a acusarlo ante el Senado por "mala conducta en el ejercicio de sus funciones". Conforme al artículo 94 de la Constitución, depositaba en el vicepresidente el despacho del Poder Ejecutivo, pues tanto él como sus secretarios del despacho ejecutivo habían presentado renuncia a sus cargos ${ }^{61}$.

El "tropezón" que se había producido entre los dos poderes no tenía antecedentes, como reconoció el presidente en su enérgica protesta ante la declaración. Mas la defensa del honor del Ejecutivo contra esa declaración injuriosa de una de las cámaras legislativas tuvo que prosperar ante semejante escándalo, con lo cual se mantuvieron en sus cargos los renunciantes ${ }^{62}$. Por su parte, el vicepresidente Márquez, quien no tuvo parte en la responsabilidad de la convención firmada con Venezuela, sería elegido por el Congreso, en una elección perfeccionadora, segundo presidente de la Nueva Granada.

\section{Epílogo}

El talante de estadista que el vicepresidente Francisco de Paula Santander demostró, con ocasión de las objeciones que interpuso a algunos proyectos de ley que habían sido aprobados por las cámaras legislativas, teniendo a la vista el ordenamiento constitucional, unos conocimientos superiores a los de los congresistas y una conciencia plena de las atribuciones del Ejecutivo, fue justificado en alguna ocasión con el principio que lo orientaba: "Tres son los principales objetos de un buen gobierno: satisfacer las necesidades de la nación, procurar la verdadera felicidad de la sociedad y fortalecerse contra los ataques exteriores" 63 .

Hablando burocráticamente, todas las objeciones fueron debatidas previamente en el Consejo de Gobierno, con lo cual el Poder Ejecutivo actuó por consenso del despacho en sus relaciones con las dos cámaras legislativas, dejando a salvo el hecho de que el

\footnotetext{
${ }^{60}$ Francisco de Paula Santander, "Comunicación dirigida al presidente del Senado, Bogotá, 6 de febrero de 1837”, en Cartas y mensajes del general Francisco de Paula Santander, 1955, vol. IX, 337-339.

${ }^{61}$ Gaceta de la Nueva Granada, 235 (27 de marzo de 1836).

62 "Las resoluciones posteriores de la cámara impidieron, es verdad, que la caída fuera mortal, pero los daños del tropezón ya están hechos, y la deshonra del país por aquellos días, consumada. No pueden ni deben ser legisladores los hombres de pasiones violentas, que en vez de mirar a la patria, miran solo sus resentimientos personales y sus deseos de hacerse célebres ante el vulgo. Las épocas de acreditar republicanismo ya pasaron; ahora lo que se necesita es juicio e imparcialidad para conservar lo que tenemos y mejorarlo prudentemente". Carta de Santander al gobernador de Mompós, Francisco Troncoso, Bogotá, 29 de abril de 1836, en Cartas y mensajes del general Francisco de Paula Santander, 1955, vol. IX, 390. 63 “Objeción presentada por el Poder Ejecutivo al proyecto de ley adicional al régimen político de los departamentos. Bogotá, 4 de abril de 1826”, Gaceta de Colombia, 267 (26 de noviembre de 1826), 3.
} 
Libertador presidente estuvo ausente de esta institución colegiada durante su primer mandato constitucional. Pero a la insistencia de Santander se debe una tradición institucional que llega hasta nuestros días, recogida por el artículo 138 de la Constitución de 1991, que es una regalía del Poder Ejecutivo: solo por su convocatoria, y por el tiempo que él determine, puede reunirse el Congreso en sesiones extraordinarias.

Efectivamente, las legislaturas de 1823, 1824 y 1833 intentaron aprobar proyectos de ley que establecieran el derecho a prorrogar la duración de sus sesiones ordinarias, establecidas por las constituciones de 1821 (90 días, prorrogables hasta 120 en caso necesario) y 1832 (60 días, prorrogables a 90 en caso necesario), sin la licencia otorgada por el Ejecutivo. En todas esas ocasiones, Santander objetó los proyectos de ley y se negó a firmarlos, fiel a su regla de conducta en este tema: aunque en "las sociedades que apenas comienzan a entrar en la carrera constitucional" era normal que se suscitaran dudas "sobre las verdaderas funciones de los poderes del Estado", las primeras constituciones de Colombia y de la Nueva Granada concedían al Ejecutivo la atribución de sancionar con su firma la prórroga de las sesiones del Congreso. En su opinión, "el honor del país y el decoro de los poderes de la república" habían otorgado al Ejecutivo el derecho a intervenir cuando el Legislativo intentara prorrogar la duración normal de sus sesiones ordinarias ${ }^{64}$.

A Santander también hay que reconocerle el esmero que puso por introducir una nomenclatura precisa en el texto de las leyes aprobadas, una exactitud y uniformidad en el lenguaje, para que los granadinos no sufrieran "una legislación oscura y complicada". Aunque no pertenecía a la generación colombiana de 1870, que podría llamarse "generación de los gramáticos"65, frecuentemente introducía en sus objeciones a proyectos de ley llamados de atención sobre los tiempos verbales y los sustantivos usados, argumentando que en las leyes se requería la mayor exactitud lingüística, y que "esta requiere una nomenclatura peculiar que, si no llega a obtenerse, nunca habrá claridad en la legislación". Un ejemplo de ese celo son sus objeciones al decreto aprobado por la legislatura de 1833 que ordenaba pagar cien pesos mensuales a John Mackintosh por cuenta de la deuda que Colombia tenía con su hermano James. Como allí se resolvía que el "jefe de la administración" debía ordenar esos pagos, el entonces presidente de la Nueva Granada recordó que desde los tiempos de las leyes de Colombia; "que en mucha parte todavía subsisten en la Nueva Granada", se habían adoptado las expresiones "presidente de la república" y "poder ejecutivo" para hablar de la jefatura del Estado. Como estas palabras ya eran generalmente conocidas y evocaban "una misma idea en la generalidad de los habitantes", no podía admitir ya la expresión "jefe de la administración" por su generalidad para cualquier empleado de la rama ejecutiva, a menos que se usara la precisa expresión "jefe de la administración de la república", pero en este caso ya se estaban "reuniendo muchos signos para manifestar una sola idea"66. Puede

\footnotetext{
${ }^{64}$ Francisco de Paula Santander, "Comunicaciones dirigidas al presidente del Senado y al Congreso, Bogotá, 26 y 29 de abril, y 3 de mayo de1833", en Cartas y mensajes del general Francisco de Paula Santander (Bogotá: Academia Colombiana de Historia, 1954), vol. VIII, 297-302.

${ }^{65}$ Miguel Antonio Caro, José Manuel Marroquín y José María Vergara, los fundadores de la Academia Colombiana de la Lengua en 1871, son las figuras más brillantes de la generación que vivió la época colombiana en la que el ejercicio del poder y la competencia entre los publicistas de los dos partidos históricos estaban íntimamente conectados con el saber gramatical y el conocimiento de los clásicos de la lengua castellana. La generación liberal precedente de (“los gólgotas,"), en cambio, era afrancesada y amante de los galicismos. Malcolm Deas, "Miguel Antonio Caro y amigos: gramática y poder en Colombia", en Del poder y la gramática y otros ensayos sobre historia, política y literatura colombianas, ed. por Malcolm Deas (Bogotá: Taurus, 2006), 27-61.

${ }^{66}$ Francisco de Paula Santander, "Comunicación dirigida al presidente del Senado, Bogotá, 7 de mayo de1833", en Cartas y mensajes del general Francisco de Paula Santander (Bogotá: Academia Colombiana de Historia, 1954), vol. VIII, 303-306.
} 
entonces decirse que la tradición granadina de pulir los textos de las leyes comenzó desde los tiempos de la experiencia colombiana de la década de 1820.

Si algo le enseñó al general Santander la experiencia de casi tres lustros al frente de las responsabilidades del Ejecutivo fue a tomar partido por ellas antes que ceder a sus deseos personales, especialmente en el caso de las contribuciones fiscales que pesaban sobre los ciudadanos. Cuando la legislatura de 1835 aprobó una ley que abolía el impuesto de alcabala menor y de fincas raíces, un "acto popular" que atraería las simpatías hacia el Estado y hasta lo beneficiaría a él como propietario de tierras e inmuebles que era, la objetó en su totalidad. Aunque los principios de economía política le dijeran que la extinción de la alcabala facilitaría el comercio interior y estimularía la acumulación de los capitales privados, aumentando la riqueza pública, la realidad del faltante que causaría en el tesoro público lo obligó a preferir que no sufrieran mengua los recursos indispensables para la existencia nacional antes que satisfacer "el contento de las poblaciones" y la alegría que les produciría la destrucción de las alcabalas.

Presentó entonces al Senado las cuentas de este impuesto particular: terminado el noveno mes de 1834 , la alcabala menor había producido 201.260 pesos y la de fincas raíces 17.241 pesos, para un total de 218.501 pesos. La proyección de esta suma permitía esperar un recaudo total de ese año del orden de 273.126 pesos. Esta era la cantidad anual que el tesoro dejaría de recaudar - importante si se considera que en los últimos nueve meses de 1834 los estancos de aguardientes habían producido 85.168 pesos-, sin que el proyecto de ley aprobado estableciera como se reemplazaría, pese a que los ingresos de esos nueve meses no habían alcanzado a cubrir los gastos públicos y que existían varias deudas pendientes por cancelar por otras leyes aprobadas por las legislaturas anteriores. Las consecuencias del déficit fiscal que se crearía eran fácilmente identificables: los empleados públicos no recibirían la totalidad de sus sueldos, generándose un descontento perjudicial al buen servicio público; los cuerpos militares no serían asistidos puntualmente, los acreedores expresarían su descontento por todos los medios.

Podría entonces esperarse una repetición de la experiencia fiscal colombiana, cuya deficiencia fiscal obligó a la legislatura de 1823 a decretar un subsidio extraordinario y a contratar un préstamo de 30 millones de pesos fuertes; la legislatura de 1824 tuvo que introducir una contribución extraordinaria y el derecho de consumo, que era la alcabala con otro nombre; y la legislatura de 1826 introdujo un auxilio extraordinario al crédito nacional. Solamente la legislatura de 1825 no introdujo algún gravamen extraordinario porque en ese año se contó con los fondos del empréstito inglés. El resultado de esa experiencia fiscal fue la pérdida del prestigio del Poder Legislativo, "porque ya se miraba cada una de sus reuniones como la amenaza de una próxima exacción pecuniaria”, y una parte de los colombianos "se alucinó hasta el extremo de persuadirse que el sistema representativo era inadaptable en Colombia, y que el pueblo debía echarse en manos de un dictador". Esta predisposición fue encontrada por el general Bolívar a su regreso del Perú, quien la halagó con el restablecimiento de la alcabala y otros impuestos heredados del gobierno español, con lo cual "cesó en derecho la república de Colombia en 1827 y desapareció del todo en 1828".

Recordó que "nada parecía más bello que el sistema liberal de rentas" establecido por el congreso constituyente de la Villa del Rosario de Cúcuta: se liberó la destilación y la venta de aguardientes, fue extinguida la alcabala y reducidos los derechos de importación, y se imaginó que la nueva contribución directa produciría millones de pesos. Después de recibir esos actos del Congreso con entusiasmo y aplauso en el exterior, el paso de los años mostró que el faltante fiscal, suplido con contribuciones extraordinarias, minó el sistema y abrió la puerta a la capitación personal, la alcabala, el tributo de indígenas y altos derechos de importación exigidos con vejación. En esa época él mismo 
se había opuesto al restablecimiento de la alcabala por el Congreso, convencido de que se trataba de "un paso retrógrado que había de desacreditar a Colombia en el mundo". Pero la experiencia obligaba a preservar a la Nueva Granada del porvenir funesto si se eliminaba ahora la alcabala, pues su supresión golpearía a las provincias (Socorro, Vélez, Mariquita, Neiva, Tunja) que solo contaban con las alcabalas y el estanco de aguardientes para sufragar los gastos de la administración pública.

Finalmente advirtió que el caso de Venezuela, donde se habían eliminado las contribuciones internas y se había fincado la subsistencia nacional sobre los derechos de importación, confiando en el tráfico mercantil de sus puertos, servía de lección: el secretario de Hacienda había tenido que pedirle a la legislatura venezolana de 1835 el establecimiento de algunas rentas internas para atender la insuficiencia de sus recursos fiscales, además de un incremento del $10 \%$ en los derechos de importación ${ }^{67}$.

Pese a tan prudentes objeciones del presidente, esta legislatura de 1835 insistió en su postura y aprobó de nuevo la abolición de las alcabalas menores y de fincas raíces en la Nueva Granada. En carta dirigida a Rufino Cuervo, quien se encontraba en París, el presidente Santander se lamentó del déficit introducido al tesoro nacional y de los males que se seguirían de la escasez de fondos para hacer frente a los gastos públicos. Reflexionó entonces sobre la impotencia del Ejecutivo ante la decisión precipitada de las cámaras por un efecto de su entusiasmo liberal: "En vano peleamos defendiendo la conservación del impuesto hasta mejores circunstancias: contra el entusiasmo no valen razones" 68 .

Otro caso de defensa del tesoro nacional contra los intentos de mermarle sus ingresos fue la objeción al decreto legislativo que en junio de 1835 concedió a Baltasar de la Torre una pensión vitalicia de diez pesos mensuales. Aunque el general Santander reconoció que el Congreso tenía el poder para conferir premios y recompensas personales a los ciudadanos que habían hecho grandes servicios a la república, en este caso la legislatura había sido engañada con falsos informes. Cuando pidió una jubilación al Ejecutivo, La Torre solo pudo probar que había servido en la factoría de tabacos de Ambalema durante 13 años y 3 meses en el tiempo republicano, y entonces se declaró sin lugar su solicitud. Aunque se trataba de una persona vieja y pobre, su trabajo no llenaba el requisito de "grandes servicios" a premiar. En este caso tenía entonces que recordar a los legisladores que la experiencia acreditaba que si los gobiernos eran pródigos de recompensas agotarían las fuentes de donde ellas nacen, "y nunca sacian a todos los pretendientes". La experiencia también demostraba que si la economía de las penas era necesaria la de los premios era indispensable, "porque más pronto se llega al término de donde se extraen las recompensas honorarias o pecuniarias"69.

La experimentada opinión de Santander sobre la naturaleza de las leyes fue

\footnotetext{
${ }^{67}$ Francisco de Paula Santander, "Comunicación dirigida al presidente del Senado, Bogotá, 9 de mayo de1835", en Cartas y mensajes del general Francisco de Paula Santander, 1955, vol. IX, 213-226. Pese a tan prudentes objeciones del presidente, esta legislatura de 1835 insistió en su postura y aprobó de nuevo la abolición de las alcabalas menores y de fincas raíces en la Nueva Granada. En carta dirigida a Rufino Cuervo (7 de agosto de 1835), quien se encontraba en París, Santander se lamentó del déficit introducido al tesoro nacional y de los males que se seguirían de la escasez de fondos para hacer frente a los gastos públicos. Reflexionó entonces: "En vano peleamos defendiendo la conservación del impuesto hasta mejores circunstancias: contra el entusiasmo no valen razones", obra citada, vol. IX, 277.

${ }^{68}$ Francisco de Paula Santander, "Carta dirigida a Rufino Cuervo, Bogotá, 7 de agosto de 1835, 16 aniversario de la batalla de Boyacá”, en Cartas y mensajes del general Francisco de Paula Santander, 1955, vol. IX, 277.

${ }^{69}$ Francisco de Paula Santander, "Comunicación dirigida al presidente de la Cámara de Representantes, Bogotá, 23 de junio de1835”, en Cartas y mensajes del general Francisco de Paula Santander, 1955, vol. IX , 267-268.
} 
expuesta durante su última administración ejecutiva, cuando objetó una ley aprobada en la legislatura de 1836 para adicionar la ley orgánica de los tribunales de la Nueva Granada. La innovación inaceptable para él consistía en trasladar el conocimiento de las apelaciones de las causas civiles y criminales por delitos comunes, falladas en primera instancia por los juzgados eclesiásticos ordinarios, a los tribunales civiles de los distritos. Este trastorno de la gradación de los tribunales que conocían juicios seguidos a los eclesiásticos no solamente violaba la superioridad jerárquica del arzobispo metropolitano, sino un acuerdo entre las potestades eclesiástica y civil que había sido consignado en una bula pontificia e incluida en la codificación de las leyes de Indias, reconocida por la jurisdicción republicana. Como algún legislador podría alegar que el poder soberano del Congreso lo autorizaba para todo, contradijo diciendo que jamás debía darse una ley solo por ejercer el poder de darla:

Y a la verdad, en la confección de las leyes y especialmente en las que alteran un orden establecido desde muchos siglos atrás, la consideración de la autoridad no es suficiente ni tal vez la principal, sino de la oportunidad, conveniencia y necesidad; porque donde la ley no es reclamada por ellas, nada hay que compense los inconvenientes, y los pueblos tienen el derecho de que no se les perturbe sin bastante motivo en sus instituciones, hábitos, usos y costumbres ${ }^{70}$.

Así como el economista Jean-Baptiste Say había dicho que tanto en la administración pública como en la moral no estaba la habilidad en querer que se haga, sino en hacer que se quiera, podría aplicarse lo mismo a la legislación: la ley será siempre ejecutable, porque su efecto no depende de la aceptación, pero "¿quién puede dudar que de la buena aceptación depende en gran parte la pronta, fácil y completa ejecución de la ley?". El legislador debía proceder con mucha previsión cuando aprobaba innovaciones y reformas bien entendidas y preparadas, reconociendo "la acción inanticipable del tiempo, la condición indispensable de la oportunidad, los medios y circunstancias". La innovación proyectada en la cadena de los tribunales que juzgaban a los eclesiásticos no había tenido en cuenta a la opinión pública, aún no preparada para aceptar la mala inteligencia entre las dos potestades, con lo cual sería recibida "con sorpresa, aflicción y repugnancia por muchos."

${ }^{70}$ Francisco de Paula Santander, "Comunicación dirigida al presidente de la Cámara de Representantes, Bogotá, 15 de enero de1836" en Cartas y mensajes del general Francisco de Paula Santander, 1955, vol. IX, 297. 


\section{Bibliografía}

CORTÁZAR, Roberto (compilador). Cartas y mensajes del general Francisco de Paula Santander, Bogotá, Academia Colombiana de Historia, 1953-1956, 10 tomos.

GACETA DE COLOMBIA. Iniciada en la Villa del Rosario de Cúcuta y continuada en Bogotá, Imprenta de Bruno Espinosa de los Monteros. No. 1 (6 sep. 1821) a No. 566 (29 dic. 1831). Edición facsimilar del Banco de la República, Bogotá, 19731975,5 tomos.

LÓPEZ, Luis Horacio (compilador). Administraciones de Santander, 1820-1838, Bogotá, Fundación Francisco de Paula Santander, 1990, 6 tomos. 